UNIVERSIDADE DE SÃO PAULO

FACULDADE DE FILOSOFIA, CIÊNCIAS E LETRAS DE RIBEIRÃO PRETO

DEPARTAMENTO DE FÍSICA

PROGRAMA DE PÓS-GRADUAÇÃO EM CIÊNCIAS

ÁREA DE CONCENTRAÇÃO: FÍSICA APLICADA À MEDICINA E BIOLOGIA

LEONARDO LIRA DO AMARAL

Programa de controle da qualidade dosimétrico, validado com auxílio de filme radiocrômico, aplicado à

Radioterapia Estereotáxica

Ribeirão Preto 


\title{
Programa de controle da qualidade dosimétrico, validado com auxílio de filme radiocrômico, aplicado à Radioterapia Estereotáxica
}

\author{
Dissertação submetida ao programa de Pós- \\ Graduação em Física Aplicada a Medicina e \\ Biologia, da Faculdade de Filosofia, Ciências \\ e Letras de Ribeirão Preto, da Universidade \\ de São Paulo, como parte dos requisitos para \\ a obtenção do título de Mestre em Ciências - \\ Área de Concentração: Física Aplicada à \\ Medicina e Biologia.
}

Orientador:

Prof. Dr. Thomaz Ghilardi Netto 
Autorizo a reprodução e divulgação total ou parcial deste trabalho, por qualquer meio convencional ou eletrônico, para fins de estudo e pesquisa, desde que citada à fonte.

Amaral, Leonardo Lira

Programa de controle da qualidade dosimétrico, validado com auxílio de filme radiocrômico, aplicados à Radioterapia Estereotáxica. Ribeirão Preto, 2012.

$$
84 \text { p. : il. ; } 30 \mathrm{~cm}
$$

Dissertação de Mestrado, apresentada à Faculdade de Filosofia, Ciências e Letras de Ribeirão Preto/USP. Área de concentração: Física Aplicada à Medicina e Biologia.

Orientador: Ghilardi Netto, Thomaz.

1. Radioterapia. 2. Programa de Controle da Qualidade em Radioterapia. 3. Filme Radiocrômico 4. Dosimetria in vivo 
Nome: Amaral, Leonardo Lira

Título: Programa de controle da qualidade dosimétrico, validado com auxílio de filme radiocrômico, aplicados à Radioterapia Estereotáxica

Dissertação submetida ao programa de PósGraduação em Física Aplicada a Medicina e Biologia, da Faculdade de Filosofia, Ciências e Letras de Ribeirão Preto, da Universidade de São Paulo, como parte dos requisitos para a obtenção do título de Mestre em Ciências Área de Concentração: Física Aplicada à Medicina e Biologia.

\section{Aprovado em:}

\section{Banca Examinadora}

Prof. Dr. Instituição:

Julgamento: Assinatura:

Prof. Dr. Instituição:

Julgamento: Assinatura:

Prof. Dr. Instituição:

Julgamento: Assinatura: 
"Deus nos fez perfeitos e não escolhe os capacitados; capacitam os escolhidos. Fazer ou não fazer algo só depende de nossa vontade $e$ perseverança."

Albert Einstein 
A meus pais, Amaral $e$ Fátima, pais exemplares, por me apoiarem em todas as etapas da vida, e minha esposa e filho, Milena e André Luiz, pela compreensão, carinho, presença e incansável apoio ao longo do período de elaboração deste trabalho. 
Agradecimentos 
A meus pais, Amaral e Fátima, que sempre me deram suporte para tudo e que nunca me deixaram desistir, que me fizeram acreditar que vale a pena lutar por um sonho, mesmo sabendo da incerteza de realizá-lo.

A minha esposa, Milena, por saber me dividir com o trabalho, por compartilhar minhas conquistas como se fossem dela e por ter sido paciente sempre que o cansaço e a preocupação me deixavam dominar.

Ao meu filho, André Luiz, que me proporciona a maior felicidade do mundo. E, por me motivar a trabalhar e estudar para lhe oferecer um futuro com mais oportunidades.

A minha irmã Manuela, por fazer parte da minha vida.

Ao meu orientador, Prof. Thomaz, por ter perdido tantas manhãs, tardes e noite me ensinando o que eu já deveria saber, por ter tido, sempre, muita paciência. E, principalmente, por ter me feito crescer, como pessoa e profissional.

Ao meu amigo e chefe, Dr. Harley, que me propiciou a oportunidade de poder conciliar o trabalho e estudo simultâneo.

A Prof. Patrícia, por ter me ajudado, mesmo que informalmente, no desenvolvimento deste trabalho.

Aos que me ensinaram a dar os primeiros passos na física da Radioterapia, Gustavo, Edenyse e Leandro. Por ter sido mais que colegas de trabalho, amigos e professores.

Aos aprimorandos da radioterapia Leandro, Marina, Jessica e Laila, que me ajudaram e contribuíram com muito esforço na obtenção dos dados presentes nesta dissertação.

Aos funcionários HCFMRP, que fizeram do ambiente de trabalho um ambiente aprendizado agradável e prazeroso.

A minha família Lira, que contribuíram com meu caráter e me transformaram numa pessoa feliz e melhor.

Aos Meus amigos de Pernambuco, que mesmo de longe sempre estiveram tão perto.

Aos meus professores dos cursos de graduação em Matemática e Física, que contribuíram ao meu amadurecimento intelectual. Em particular aos professores Airton e Paulo Figueiredo da Matemática e Albino do curso de física, por serem sempre tão solícitos e conselheiros. 
Às secretárias do Departamento Física, em especial à Nilza, secretária do programa de pós-graduação em Física Aplicada à Medicina e Biologia por todo suporte durante o período de pós-graduação.

A CAPES, pelo apoio financeiro em todos estes meses de pós-graduação.

A todos que, de alguma forma, contribuíram direta ou indiretamente para este trabalho.

Finalmente, e talvez o agradecimento mais importante, a Deus, por nunca ter me abandonado, por ser meu conforto nas horas mais difíceis e por ter colocado todas essas pessoas em minha vida. 
Resumo 
Amaral L.L. Programa de controle da qualidade dosimétrico, validado com o auxílio do filme radiocrômico, aplicado à Radioterapia Estereotáxica. Dissertação (Mestrado). Ribeirão Preto: Faculdade de Filosofia, Ciências e Letras de Ribeirão Preto, Universidade de São Paulo; 2012. 84 p.

A Radioterapia de lesões cerebrais próximas a estruturas críticas necessitam de uma alta precisão na localização e na dose. O rigor na liberação da dose deve ser acompanhado por um preciso controle da qualidade nos aparelhos que envolvam a prática. O comissionamento do sistema de planejamento consiste em averiguar e confirmar os cálculos realizados pelo sistema. Porém, mesmo com todo controle da qualidade no comissionamento, existem vários aspectos que podem influenciar na administração da dose no volume alvo, o que exige a necessidade de se fazer uma avaliação final, no ato do tratamento, in vivo. O objetivo deste trabalho é desenvolver uma técnica de dosimetria in vivo como parte de um programa de controle da qualidade em radioterapia estereotáxica. Na técnica de dosimetria in vivo, utilizaram-se segmentos de filme radiocrômico, com dimensões de $1 \times 1 \mathrm{~cm}^{2}$, acoplados na área externa ao colimador formado por micro-lâminas, Moduleaf. Estes filmes foram inseridos na região central do feixe. Os filmes foram irradiados e calibrados para obtenção dos fatores campos, na configuração da técnica. Com estes dados foi elaborado um programa computacional, o qual calcula a densidade relativa que um filme deve adquirir quando submetido a uma exposição nesta configuração. Como a técnica de dosimetria in vivo usa os dados do TPS, validaram-se alguns parâmetros do comissionamento do TPS. Complementando o estudo da dosimetria in vivo foram avaliados cinco planos não co-planares, sendo o primeiro com 15 campos e os outros com 25 campos. Antes de iniciar o procedimento o segmento de filme era acoplado ao aparelho e após a execução do tratamento a densidade ótica era avaliada e comparada com a calculada pelo programa desenvolvido. No comissionamento, todas as dosimetrias relativas apresentaram diferenças percentuais menores que $2 \%$, quando comparados os resultados medidos com os calculados pelo sistema de planejamento. No desenvolvimento da técnica de dosimetria in vivo, a diferença percentual média da verificação dosimétrica, no momento da irradiação, comparado com a calculada pela planilha foi de 1,5\%, enquanto que a dosimetria absoluta aplicada ao controle da qualidade convencional foi aprovada com diferença percentual média de $2,5 \%$ e a função gama média encontrada foi de $97,9 \%$ dos pontos aprovados com critério de aceitação $\Delta \%=2 \%$ e $\Delta \mathrm{D}=2 \mathrm{~mm}$. Logo, todos os dados estão em concordância com os limites estabelecidos pelo TRS-430. Desta forma, conclui-se que foi desenvolvida uma técnica de dosimetria in vivo como parte de um programa de controle da qualidade em radioterapia estereotáxica com filme radiocrômico, já que foram confirmados os parâmetros básicos do comissionamento do sistema de planejamento e a técnica foi validada com o controle de qualidade convencional nos cinco planos analisados.

Palavras-chave: Radioterapia, Programa de Controle da Qualidade em Radioterapia, Filme Radiocrômico e Dosimetria in vivo. 
Abstract 
Amaral L.L. Dosimetric quality assurance with the help of the radiochromic film, applied to stereotactic radiotherapy. Dissertation. Ribeirão Preto: Faculdade de Filosofia, Ciências e Letras de Ribeirão Preto, Universidade de São Paulo; 2012. 84p.

Radiation therapy of brain lesions near critical structures requires a highly accurate location and dose. The accuracy in dose delivery should be accompanied by an accurate quality control in devices involving the practice. The commissioning of the planning system is to ascertain and confirm the calculations performed by the system, but even with all quality control in the commissioning, there are several aspects that may influence the dosing the target volume, which necessitates the need to make a final assessment at the time of treatment, in vivo. The objective of this work is to develop a technique for in vivo dosimetry as part of quality assurance in stereotactic radiotherapy. In vivo dosimetry technique, we used segments of film radiocromico, with dimensions of $1 \times 1 \mathrm{~cm}^{2}$, coupled to the external area formed by the micro-collimator blades, Moduleaf. These films were inserted in the central region of the beam. The films were irradiated and calibrated to obtain factors of fields in the configuration of the technique. With these data we designed a computer program which calculates the relative density of a film must acquire when subjected to an exposure in this setting. As the technique of in vivo dosimetry using data from the TPS, validated parameters are the commissioning of the TPS. Complementing the study of in vivo dosimetry were evaluated five non-coplanar plans, the first with 15 fields and the other with 25 fields. Before starting the procedure, the film segment was attached to the unit and after the treatment is the optical density was measured and compared with those calculated by the program developed. At commissioning, all presented on dosimetry percentage differences less than $2 \%$, when comparing the measured results with those calculated by the planning system. In developing the technique of in vivo dosimetry, the mean percent difference dosimetry verification at the time of irradiation compared with the calculated by the sheet was $1.5 \%$, while the absolute dosimetry applied to the conventional quality control has been approved as mean percent difference $2.5 \%$ and the gamma function mean was $97.9 \%$ of the points agreed with the acceptance criterion $\Delta \%=2 \%$ and $\Delta \mathrm{D}=2 \mathrm{~mm}$. Therefore, all data are in agreement with the limits set by TRS430. Thus, we conclude that we have developed a technique for in vivo dosimetry as part of a quality assurance in stereotactic radiotherapy radiocrômico film, since some parameters were confirmed to commissioning the planning system and the technique was validated with control quality standard in five plans analyzed.

Keywords: Radiotherapy, quality assurance, radiochromic film, in vivo dosimetry. 
Siglas e Abreviaturas 
AAPM: $\quad$ American Association of Physicists in Medicine

AL: $\quad$ Acelerador Linear

Ceq Campo Equivalente

CQ: $\quad$ Controle da Qualidade

DDDC Dependência Dosimétrica da Dimensão do Campo

Dif. \% Diferença Percentual

DNA: $\quad$ Deoxyribonucleic acid

DR: $\quad$ Densidade Relativa

DTA: Distance-to-agreement

FC: $\quad$ Fator Campo

HCFMRP: Hospital das Clínicas da Faculdade de Medicina de Ribeirão Preto

IAEA: International Atomic Energy Agency

ICRU: $\quad$ International Commission on Radiation Units and Measurements

IMRT: $\quad$ Intensity Modulated Radiation Therapy

MLC: $\quad$ Multleaf Collimator

MMLC: $\quad$ Micro Multleaf Collimator

MU: $\quad$ Monitors Unit

PDP: $\quad$ Porcentagem de Dose Profunda

SAD: $\quad$ Source Axis Distance

SSD: $\quad$ Source Skin Distance

TC: $\quad$ Tomógrafo Computadorizado

TLD: $\quad$ Thermoluminescent dosimetry

TMR: $\quad$ Tissue Maximum Ratio

TG: $\quad$ Task Group

TPS: $\quad$ Treatment Planning Systems

USP: $\quad$ Universidade de São Paulo 
Figura 2.1 - Imagem de uma tomografia do crânio com diferentes densidades eletrônicas...... 11

Figura 2.2 - Ilustração do conceito da função gama. A curva vermelha representa a imagem de referência e a azul, a imagem analisada - Fonte: Varian Medical Systems, Reference Guide for Portal Dosimetry

Figura 2.3 - Regiões que Venselaar utilizou para diferenciar os cretérios de tolerancia para aceitabilidade das dosimetrias de referências. Fonte TRS - 430. (49).

Figura 2.4 - Critérios das diferenças percentuais, $\delta$, descritas por Venselaar em várias localizações de medidas do feixe no obejeto simulador. Fonte TRS - 430.(49)

Figura 3.1 - Objetos Simuladores: a) água sólida, b) alumínio, c) cortiça, d) objeto simulador cúbico de água sólida.

Figura 3.2 - Conjunto dosimétrico. Eletrômetro Dose1 e câmara de ionização CC13.............23

Figura 3.3 - Configuração das irradiações para dosimetria de referência com mMLC............25

Figura 3.4 - Configuração para a determinação da dose de referência com objeto simulador constituído por água sólida e cortiça.

Figura 3.5- Configuração para a determinação da dose de referência com o objeto simulador constituído de água sólida e alumínio.....

Figura 3.6 - Configuração utilizada na irradiação dos segmentos de filmes. No detalhe o filme posicionado no eixo central da saída do feixe.

Figura 3.7 - Exemplo de um plano com 25 campos realizado em TPS. Em destaque esta a imagem do CT do objeto simulador com a câmara posicionada no centro. $O$ filme esta posicionado na convergência das linhas azuis a $1 \mathrm{~cm}$ acima da câmara.

Figura 4.1 - Curvas de isodose fornecidas pelo TPS, com os campos 30 x 30, 50 x 50 e 100 x $100 \mathrm{~mm}^{2}$ habilitados simultaneamente no objeto simulador composto por água e cortiça. a) curvas de isodose sem aplicar a correção de heterogeneidade. b) curvas de isodose aplicando a correção de heterogeneidade.

Figura 4.2 - Curvas de isodose, fornecidas pelo TPS, com os campos 20 x 20, 30 x 30, 50 x 50 e $100 \times 100 \mathrm{~mm}^{2}$ habilitados simultaneamente no objeto simulador composto por água e alumínio. a) curvas de isodose sem aplicar a correção de heterogeneidade. b) curvas de isodose aplicando a correção de heterogeneidade. 35

Figura 4.3 - Gráfico das densidades relativas em função das unidades monitoras dos segmentos de filmes utilizada na calibração da dosimetria in vivo. 
Lista de Tabelas 
Tabela 4.1 - Comparação entre as dose adquiridas no sistema de planejamento e as doses medidas com a câmara de ionização, nos campos circulares, para os campos equivalentes de 30,$6 ; 40,4 ; 50,3 ; 70,2$ e $100 \mathrm{~mm}$.

Tabela 4.2 - Comparação entre as doses, em campos quadrados, adquiridas no sistema de planejamento e a câmara de ionização, no objeto simulador composto por água sólida e cortiça.

Tabela 4.3 - Comparação entre as doses, em campos quadrados, adquiridas no TPS e a câmara de ionização posicionada no objeto simulador composto por água sólida e alumínio. 35

Tabela 4.4 - Densidade relativa dos filmes expostos a 100 UM e 300 UM na configuração da técnica de dosimetria in vivo.

Tabela 4.5 - Dados da Dependência Dosimétrica da Dimensão do Campo, a partir das densidades relativas (DR) em função do campo equivalente (Ceq).

Tabela 4.6 - Resultado das diferenças percentuais entre as densidades relativas medidas e a calculadas pela planilha desenvolvida na dosimetria in vivo. 38

Tabela 4.7 - Diferença percentual entre o valores medidos com câmara de ionização e o calculado pelo TPS.

Tabela 4.8 - Porcentagem dos índices gama aprovados nos planos usados para validação da técnica de dosimetria in vivo.

Tabela 4.9 - Desvio médio, desvio padrão e limite de confiança de todas as dosimetrias de referência realizadas neste trabalho. 
Sumário 


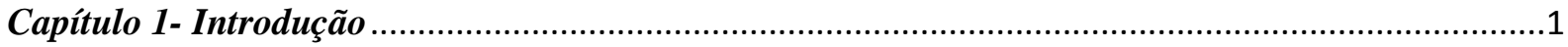

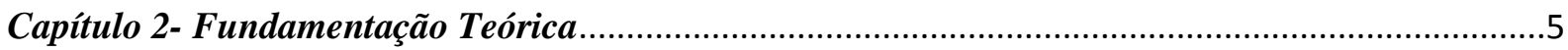

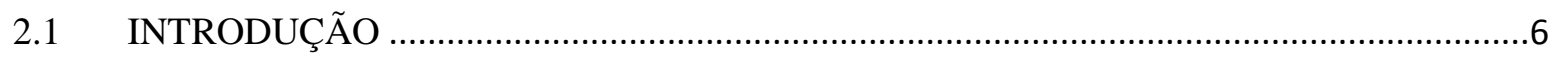

2.2 ALGUNS ASPECTOS DE RADIOTERAPIA …............................................................

2.3 COMISSIONAMENTO DO ACELERADOR LINEAR ......................................................

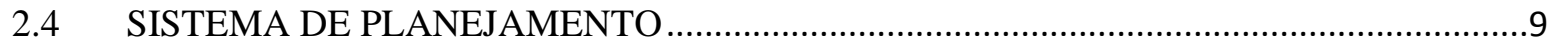

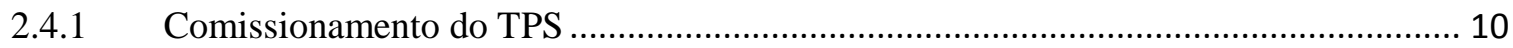

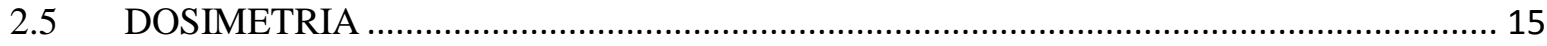

2.5.1 Protocolo da IAEA TRS-398 para feixe de fótons de alta energia................................ 16

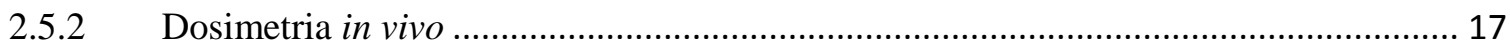

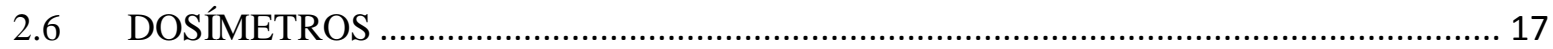

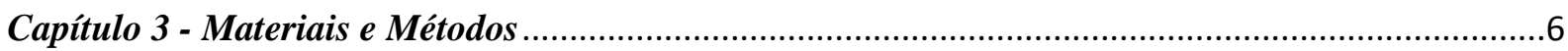

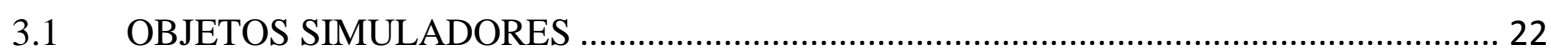

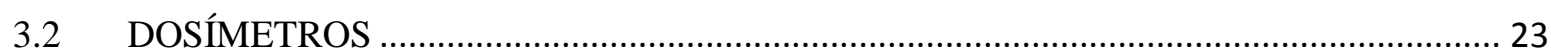

3.2.1 Câmara de ionização e eletrômetro ……………………........................................ 23

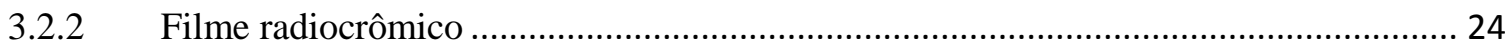

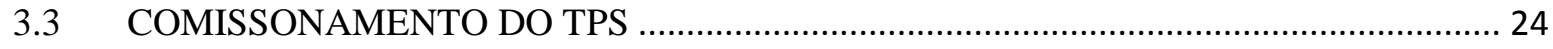

3.3.1 Dosimetria de referência em campos diretos com mMLC ............................................. 25

3.3.2 Dosimetria de referência em objetos simuladores heterogêneos com mMLC ............... 26

3.4 DESENVOLVIMENTO DA TÉCNICA DE DOSIMETRIA IN VIVO …......................... 27

3.5 AVALIAÇÃO DA TÉCNICA DE DOSIMETRIA IN VIVO EM CINCO PLANOS ........... 29

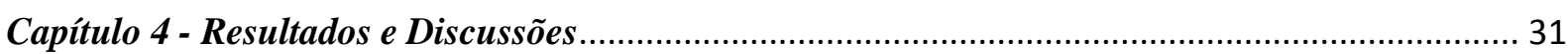

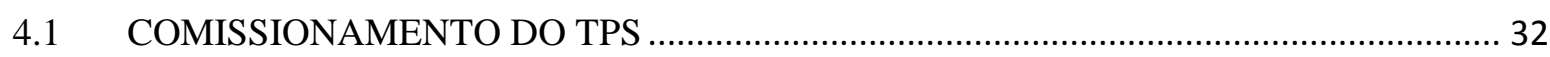

4.1.1 Dosimetria de referência em campos com mMLC .................................................... 32

4.1.2 Dosimetria de referência em objetos simuladores heterogêneos com mMLC ……....... 33

4.2 DESENVOLVIMENTO DA TÉCNICA DE DOSIMETRIA IN VIVO ............................... 35

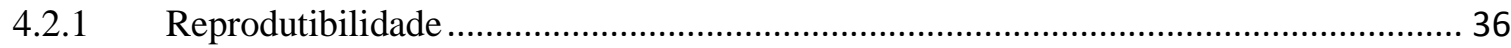

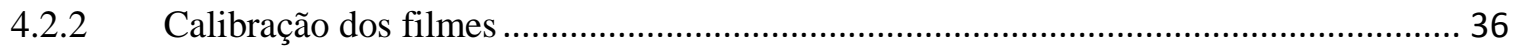

4.2.3 Dependência Dosimétrica da Dimensão do Campo ……………………...................... 37

4.3 AVALIAÇÃO DA TÉCNICA DE DOSIMETRIA IN VIVO EM CINCO PLANOS ......... 38

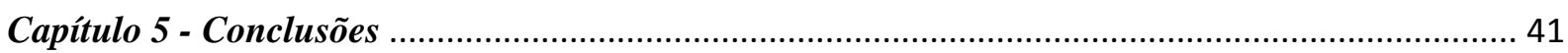

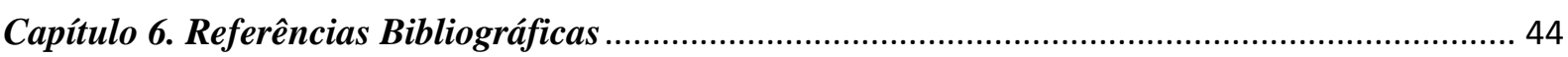




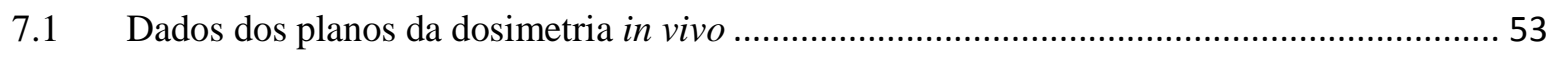

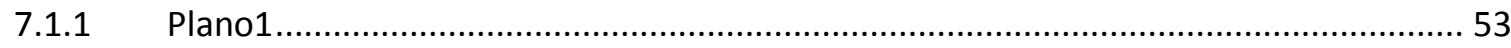

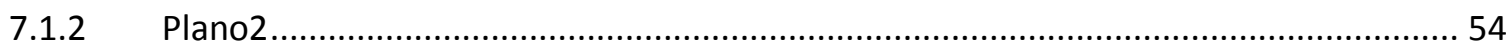

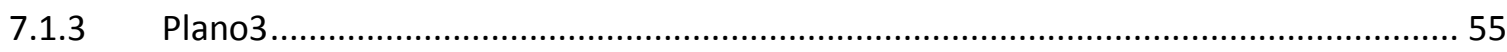

7.1.4 Plano4

7.1.5 Plano5

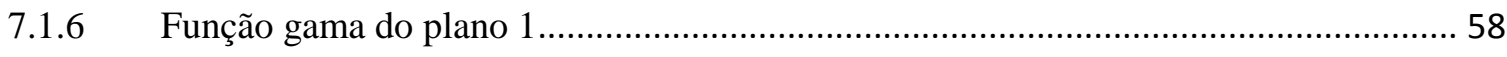

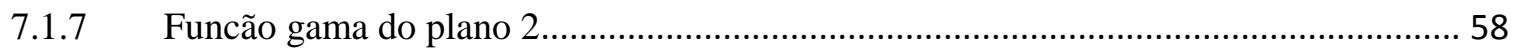

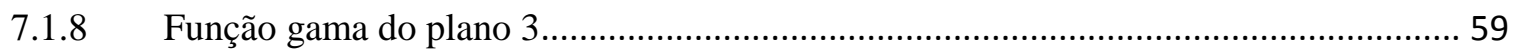

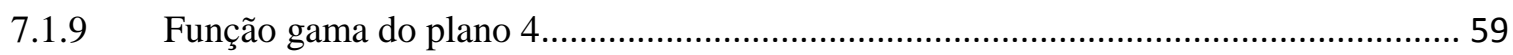

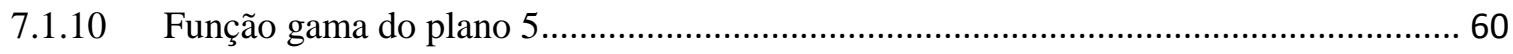

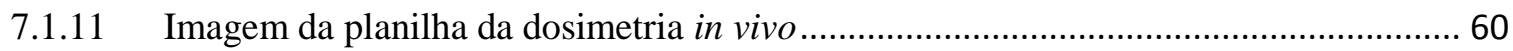


Capítulo 1- Introdução 


\section{INTRODUÇÃO}

Os tumores cerebrais acometem todos os grupos etários, sendo responsáveis por cerca de 175 mil mortes anuais no mundo. Embora os tumores malignos cerebrais representem apenas $2 \%$ de todos os tipos de neoplasias malignas, eles são frequentemente associados a importantes comprometimentos da qualidade de vida dos pacientes, além do grande impacto social que representa esta doença(1).

Apesar dos avanços no tratamento dos tumores cerebrais, os dados de sobrevida dos pacientes continuam desanimadores, propiciando diversas investigações no manejo clínico e individualização terapêutica $(2,3)$. A radioterapia tridimensional possibilitou maiores doses de radiação, o que promoveu melhor sobrevida dos pacientes, no entanto, estudos que adotaram doses acima de 60 Gy concluíram pela ausência de benefício em sobrevida, como também pelo aumento das possibilidades de efeitos colaterais quando utilizado apenas a técnica tridimensional. A radioterapia se destaca no tratamento destes tumores, no entanto, existem dúvidas a respeito da eficácia do aumento de dose de radiação liberada ao volume-alvo, sem que seja estabelecido a acurácia da administração da dose $(3,4)$.

A Radioterapia é uma técnica de tratamento que utiliza radiação ionizante a fim de eliminar células não desejadas do organismo humano, como as neoplasias cerebrais, no entanto, é necessário um controle rigoroso da radiação para diminuir a agressão às células sadias $(5,6)$. A radiocirurgia estereotáxica libera feixes de radiação com precisão de um milímetro, centrado na lesão intra-cranial em uma única fração. Entretanto, muitas lesões possuem dimensões maiores e existe a indicação de dividir a dose em varias aplicações, o nome desta técnica, fracionada, é denominada radioterapia estereotáxica $(7,8)$. Os aparatos estereotáxicos, desta técnica, garantem uma maior exatidão na localização do volume alvo, porém é necessário um programa da qualidade adequado a fim de controlar a liberação da dose.

Antes da autorização de funcionamento de qualquer equipamento para aplicações terapêuticas é necessário conhecer apropriadamente os seus parâmetros físicos(9, 10). O comissionamento de um acelerador linear (AL) é o procedimento que determina os dados 
dosimétricos do equipamento. Alguns destes dados são: Porcentagem de Dose Profunda (PDP), Relação Tecido Máximo (TMR, do inglês Tissue Maximum Ratio), Fatores de espalhamento, Fatores off-axis, distribuição volumétrica da dose, fatores de transmissão além de outros(11). Quando existe, é necessário realizar também o comissionamento dos colimadores multilâminas(12). Estes dados dosimétricos são geralmente coletados com câmara de ionização, mas devem ser inter-comparado ou até mesmo substituído por dosímetros mais adequados(12-18).

A câmara de ionização é um excelente detector de radiação, porém seu sinal diminui com a redução do seu volume sensível. Desta forma, é prudente comparar os dados do comissionamento com outros sistemas de dosimetria(13, 18, 19). Os filmes são tipos de dosímetros muito utilizados, pois são de fácil acesso, baixo custo e boa resolução espacial(20). Uma desvantagem dos filmes convencionais é sua variação de comportamento devido a parâmetros relativos à revelação, pois sofrem muita influencia com a flutuação de temperatura e com contaminação dos químicos envolvidos neste processo(21). Atualmente, existe um tipo de filme que não necessita de revelação, o filme radiocrômico, o qual não sofre influencia significativa da luz e possui pequena dependência energética(22-25).

O rigor na liberação da dose também deve ser acompanhado por um preciso controle da qualidade nos aparelhos que envolvem a prática(26). O comissionamento do sistema de planejamento (TPS, do inglês Treatment Planning Systems) consiste em averiguar e confirmar os cálculos dosimétricos realizados pelo TPS com aferições nos aceleradores lineares $(8,17$, 27, 28). Com este objetivo, são simulados diversos tipos de planejamentos, com diversas configurações de campo, de gantry e outros parâmetros físicos. Desta forma, durante a realização do comissionamento são simuladas diversas formas possíveis de tratamento para garantir a qualidade das informações apresentadas pelo TPS.

Mesmo controlando o processo da qualidade no comissionamento existem vários aspectos que podem influenciar na administração da dose durante a radioterapia. Assim sendo, a realização de uma dosimetria individual antes de cada tratamento é fundamental para confirmar o processo do planejamento, porém, ainda não garante a liberação da dose no momento da terapêutica, assim, existe a necessidade de se fazer uma avaliação final, no ato do tratamento, caracterizada pela dosimetria in vivo(29-31).

Assim, é imperativo que uma dosimetria in vivo deva ser realizada, mas na radioterapia estereotáxica existem diferentes campos não co-planares com dimensões 
reduzidas que dificultam a aplicação dos métodos convencionais que posicionam os dosímetros sobre a pele do paciente(32-35).

Pelo exposto, o objetivo deste trabalho é desenvolver uma técnica de dosimetria in vivo, como parte de um programa de garantia da qualidade em radioterapia estereotáxica, utilizando filme radiocrômico, em Acelerador Linear com colimadores compostos por microlâminas (mMLC, do inglês Micro Multleaf Collimator). A técnica de dosimetria in vivo desenvolvida neste trabalho utiliza dados importantes do sistema de planejamento, assim, para garantir a cofiabilidade da técnica foram confirmados alguns parâmetros do comissionamento do TPS em Radioterapia Estereotáxica e depois se validou a técnica de dosimetria in vivo em cinco planos com um controle da qualidade convencional.

No capitulo 2 é apresentado à fundamentação teórica abordando aspectos teóricos, físicos e clínicos, importantes para o entendimento desta dissertação. Este capítulo é subdividido em introdução, alguns aspectos da radioterapia, comissionamento do acelerador linear, sistema de planejamento, dosimetria e dosímetros.

Os matérias e métodos aplicados no desenvolvimento deste trabalho são descritos no capítulo 3, onde são expostos os objetos simuladores empregados e os dosímetros, além das metodologias empregadas no comissionamento do TPS, no desenvolvimento da técnica de dosimetria in vivo e na avaliação da técnica em cinco planos.

Os dados envolvidos neste trabalho são apresentados, analisados e discutidos na capitulo 4. Assim como, no capítulo 3, os resultados e discussões são divididos em comissionamento do TPS, desenvolvimento da técnica de dosimetria in vivo e na avaliação da técnica em cinco planos.

No capítulo 5 são apresentadas as conclusões, abordando aspectos mais relevantes do comissionamento do TPS, da metodologia empregada para o desenvolvimento da dosimetria in vivo e da sua avaliação nos cinco planos. Finalmente, no apêndice, são apresentados os dados dos planejamentos utilizados no desenvolvimento da técnica de dosimetria in vivo, as imagens das funções gama e as imagens da planilha de cálculo desenvolvida neste trabalho. 
Capítulo 2- Fundamentação Teórica 


\section{FUNDAMENTAÇÃO TEÓRICA}

\subsection{INTRODUÇÃO}

A radioatividade entrou para a história em 1896. Naquele ano, o fisco francês Antoine Henri Becquerel descobriu que um minério de Urânio emitia radiações espontaneamente. Em 1898, o casal Pierre e Marie Curie obteve êxito em separar 1g de uma desconhecida substância radioativa, a partir de uma tonelada de minério. Essa substância ficou conhecida como polônio, em homenagem a Marie Curie, que era polonesa. Por desconhecer as graves consequências das emissões radioativas para o organismo, Marie Curie tornou-se uma das muitas vítimas da radioatividade, desenvolvendo leucemia. Becquerel, que também desconhecia o perigo, padeceu meses devido a uma ferida na coxa devido aos efeitos da radiação. A lesão era causada por um pedaço de material radioativo que ele carregava no bolso para demonstração em aula. Somente algum tempo depois os físicos Ernest Rutherford (1871-1937) e Frederic Soddy (1877-1956) demonstraram que ocorre uma transmutação química de elementos no processo radioativo(36).

A radiação ao interagir com o organismo humano pode danificar as células em nível molecular. As radiações podem ser classificadas em radiações ionizantes e não ionizantes (37). As radiações não ionizantes, como a luz, não ionizam os átomos, logo não danificam o DNA. As radiações ionizantes são produzidas por partícula ou radiação eletromagnética, com energia suficientemente alta para interagir com a matéria e ionizar seus átomos(38-40). Desta forma, as radiações ionizantes podem danificar as células do organismo humano. Os efeitos podem acontecer com uma ação direta, quando a radiação interage diretamente com a molécula de DNA, ou indiretamente quando interage com a água formando um radical livre e este, por sua vez, reage com a macromolécula de DNA(37). 


\subsection{ALGUNS ASPECTOS DE RADIOTERAPIA}

Como a radiação ionizante possui o poder de lesar as estruturas biológicas, a radioterapia a utiliza para danificar células cancerígenas, o que é conseguido através de diversas técnicas, que são aplicadas conforme a necessidade, dependendo da localização e do tipo da doença envolvida(41).

A radioterapia divide-se em dois grandes grupos: teleterapia e braquiterapia. Em procedimentos teleterápicos a fonte radioativa se encontra longe do paciente enquanto que os tratamentos braquiterápicos são realizados próximo ou em contato com as lesões. $\mathrm{Na}$ teleterapia existem diferentes técnicas importantes: A radioterapia convencional, conformacional, IMRT, radioterapia estereotáxica e radiocirurgia $(42,43)$.

Radiocirurgia estereotáxica, ou simplesmente radiocirurgia, utiliza um sistema de coordenadas espaciais para localizar as lesões, permitindo tratá-las com inúmeros feixes de radiação sem intervenção cirúrgica. A radiocirurgia é a radioterapia que libera feixes de radiação em uma única fração. Quando é realizada em mais de uma aplicação esta técnica é denominada de radioterapia estereotáxica(44). Ela é uma técnica de tratamento que através de aparatos estereotáxicos permite garantir a localização do alvo de tratamento podendo ser executada com Aceleradores Lineares, com várias fontes de cobalto como Gamma Knife, ou com um robô chamado Cyber Knife, como também pode ser utilizado feixes de fótons, prótons, íons de Hélio e nêutrons. Apesar da variedade, existe muita semelhança entre todas as técnicas de radioterapia estereotáxica. No Brasil, o equipamento mais utilizado é o Acelerado Linear. Uma prática muito utilizada nestes equipamentos envolve colimadores circulares chamados de cones, onde pode ser utilizado um ou vários isocentros para liberar a dose em arcos de radiação. Uma tecnologia que esta crescendo atualmente é a de envolver a lesão em colimadores dinâmicos, onde são necessários vários campos para distribuir a radiação e minimizar os efeitos colaterais nos tecidos sadios. Outra técnica é o arco-dinâmico, onde existe o arco da primeira técnica com os colimadores dinâmicos da segunda. O controle da liberação da dose em radioterapia estereotáxica é altamente importante e consiste de várias etapas: Controle das imagens radiológicas usadas nos planejamentos, localização perfeita da área de tratamento, imobilizadores adequados e maior confiança na liberação da dose.

Antes do tratamento o paciente é submetido a uma tomografia com fiduciais acoplados na região cranial, e o registro das imagens é realizado para segmentação das estruturas de 
interesse, a visualização da lesão é geralmente auxiliada por imagens de ressonância magnética. O planejamento é realizado em um software específico, denominado sistema de planejamento. Nele, o neurocirurgião e o radioterapêuta delimitam o volume alvo e as estruturas de risco que devem ser protegidos. O físico médico realiza o plano de tratamento, como a escolha da melhor composição de campos para o plano. O objetivo é liberar uma dose elevada no alvo e as minimizar nos órgãos de risco com a finalidade de diminuir os efeitos colaterais da radiação $(26,45,46)$.

Em um tratamento típico, grupos de feixes convergem para um único ponto no espaço, o isocentro. A forma da abertura do feixe é definida pelos colimadores secundários que estão situados mais próximos do paciente a fim de reduzir a penumbra da radiação. Estes colimadores podem ser fixos em forma de circunferência ou variável com a forma da lesão.

Devido à alta exatidão, o processo deve minimizar os eventos que possam induzir ao erro. Programas de controle da qualidade devem ser rígidos, conhecidos e seguidos por toda a equipe(12, 27).

\subsection{COMISSIONAMENTO DO ACELERADOR LINEAR}

Para o cálculo da dose de radiação no paciente é necessário se conhecer os dados dosimétricos do equipamento de tratamento. A coleta dos dados dosimétricos de um AL é chamada de comissionamento dosimétrico do Acelerador Linear, sendo que alguns dos dados que o compõe são: Porcentagem de Dose Profunda, Relação Tecido Máximo, Fator de Espalhamento, Distribuição Volumétrica da Dose e Fatores de Transmissão. Porcentagem de Dose Profunda (PDP) é a relação percentual entre a dose na profundidade no eixo central do feixe com a dose na profundidade de valor máximo, com a distância fonte superfície (SSD) constate. O TMR é a mesma relação mantendo a distância fonte detector, neste caso a distância fonte superfície não é importante. Fator de Espalhamento é a relação da dose, no eixo central, na profundidade de máximo, entre o campo $10 \times 10 \mathrm{~cm}^{2}$ e as outras dimensões de campo, seu valor é adquirido dividindo a medida realizada no tamanho de campo analisado pela medida no campo $10 \times 10 \mathrm{~cm}^{2}$. Fator off-axis é a relação entre a dose no eixo central do feixe e fora desse eixo, em várias profundidades. Distribuição volumétrica, como próprio nome diz é a distribuição da dose no volume, com o qual se verifica a distribuição da dose nos 
eixo in plane e cross plane em várias profundidades. Fator de transmissão é a relação, na profundidade de máxima dose, entre a dose sem e com o objeto de transmissão, como bandeja, blocos e colimadores $(27,47)$.

\subsection{SISTEMA DE PLANEJAMENTO}

O TPS é uma ferramenta importante em radioterapia, o qual possibilita simular rapidamente as interações do feixe radioativo no organismo humano. A base de cálculo de um sistema de planejamento são as imagens radiológicas por ele recebidas. Os dados da imagem radiológica, geralmente produzidas por tomografia computadorizada, são usados em conjunto com uma descrição matemática que através de um modelo anatômico, detalhado do paciente, ilustra a distribuição de dose com elevado grau de exatidão(7).

Os planejamentos estereotáxicos requerem alta precisão e exatidão para administrar a dose de radiação em pequenos alvos de tratamento e por diversas vezes em regiões profundas e próximas às áreas funcionais do cérebro. A otimização do planejamento para obtenção das configurações de arcos com capacidade de cálculo de dose empregado na clínica de radioterapia é realizada pelo TPS. Ainda, a localização dos fiduciais do CT e o seu co-registro automático com as imagens de ressonância magnética permitem a verificação de pontos anatômicos combinando o planejamento às etapas de identificação das estruturas alvos, planos e composições de campos para a obtenção das configurações dos arcos estereotáxicos.

O TPS, a depender do modelo, constitui de algoritmos de cálculos diferentes, a escolha do algoritmo do cálculo de dose, deve levar em consideração a rapidez e a precisão. O cálculo da dose deve ser rápido o suficiente para tornar o planejamento do tratamento viável, contudo devem apresentar no mínimo uma precisão adequada para tornar confiável a correlação entre a dose administrada e a planejada. Entre os algoritmos de cálculo de dose mais usados estão o pencil beam, Superposition, Convolution e Monte Carlo. O pencil bean é um modelo de cálculo mais rápido, porém não é o mais adequado quando o volume alvo apresenta diferença acentuada na densidade eletrônica(48). 


\subsubsection{Comissionamento do TPS}

Os dados coletados no comissionamento do Acelerador Linear são usados pelo sistema de planejamento para efetuar os cálculos de distribuição da dose, sendo que a precisão no cálculo da dose depende da transcrição dos dados do comissionamento do acelerador linear realizada pelo usuário. Desta forma, o comissionamento do sistema de planejamento consiste basicamente em averiguar se esses dados estão sendo processados corretamente.

Os testes do comissionamento do TPS podem ser divididos em testes dosimétrico e não dosimétricos. Os testes dosimétricos avaliam os cálculos de dose realizados no TPS e os compara com as medidas dosimétrica realizadas no $\mathrm{AL}$ enquanto que, os testes não dosimétricos avaliam se as configurações do TPS estão em concordância com as do AL. Um exemplo disto é a avaliação de que o ângulo de gantry, mesa e colimador estão no mesmo sistema de coordenadas(49).

Um teste muito importante é a verificação da exatidão do volume alvo nos procedimentos de radioterapia estereotáxica, no qual, o objeto simulador passa por todos os procedimentos que o paciente realiza nos procedimentos desta técnica de tratamento, como: realização da imagem tomográfica com os aparatos estereotáxicos, delimitação da estrutura de avaliação, determinação das coordenadas estereotáxicas pelo TPS e averiguação no AL destas coordenadas. Outro teste importante avaliado no comissionamento é do isocentro radioativo do AL, neste teste, chamado de Wiston Lutz, realiza-se um portal de uma esfera pequena em várias configurações de campo, co-planar e não co-planar a fim de avaliar se o AL possui um isocentro adequado para qualquer configuração de campo $(9,50,51)$.

Os testes mais importantes do comissionamento dosimétrico do TPS consistem em simular diversas situações clínicas e as confirmar com medidas realizadas em objetos simuladores homogêneos e heterogêneos. Uma das principais incertezas no cálculo da dose é devido à presença de tecidos heterogêneos no organismo humano, por exemplo, o crânio, possui a calota craniana com alta densidade eletrônica, e os seios da face que apresentam baixas(52). A figura 2.1 apresenta a imagem de um crânio com diversas densidades eletrônicas, pode-se observar que a figura apresenta diversos graus de cinza, quanto mais escuro a intensidade da cor menor é a densidade eletrônica. 


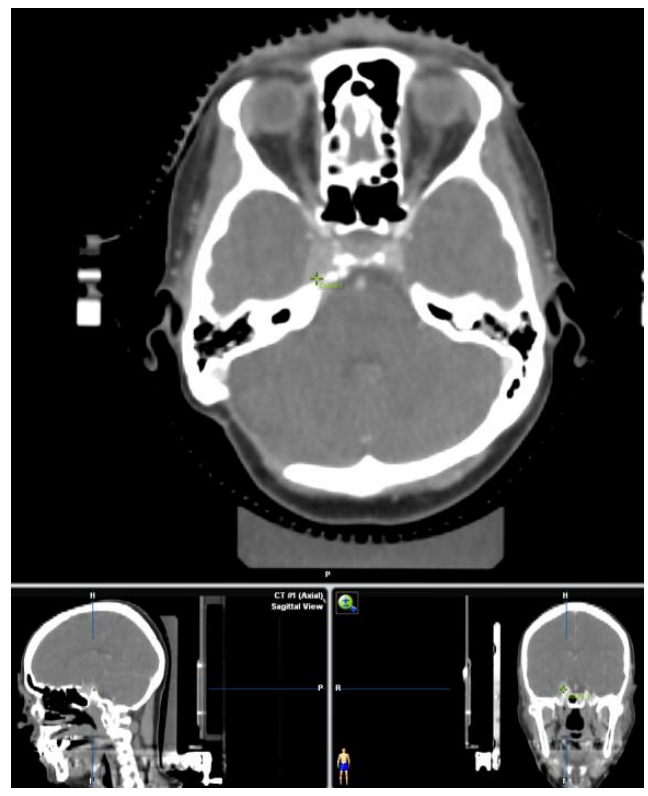

Figura 2.1 - Imagem de uma tomografia do crânio com diferentes densidades eletrônicas.

Os testes dosimétricos são importantes para verificar se a dose esta sendo liberada no alvo de modo satisfatório, esta analise é determinada através de uma dosimetria de referência em diversas configurações de feixes simples com campos quadrados e gantry a zero grau, até configurações mais complexas com campos não quadrados e feixes não co-planares. A distribuição volumétrica da dose também deve ser analisada através da analise da função gama entre os dados coletados no aparelho e os dados oferecidos pelo Sistema de Planejamento.

A função gama é um índice que compara diferenças de distância e dose a partir de critérios de aceitação pré-defendidos pelo usuário. Os critérios usados são a diferença percentual da dose $(\Delta \mathrm{D})$ e a distância de concordância da distribuição de dose $(\Delta \mathrm{r})$ chamada em inglês de DTA distance-to-agreement. Quando é necessário comparar duas fluências de dose, a função gama checa cada ponto da primeira com todos os outros pontos da segunda distribuição, e analisa se cada um destes pontos está de acordo com os critérios determinados pelo usuário, estes critérios são representados pela elipse na figura 2.2, se um ponto da primeira curva encontrar algum ponto da segunda que o $\Delta \mathrm{D}$ e o $\Delta \mathrm{r}$ estão dentro dos critérios, ou seja, dentro da elipse apresentada na figura 2.2, então o índice gama esta aceitável e seu valor será menor que 1, caso contrário, não será aceito e seu valor será maior que 1(53). 


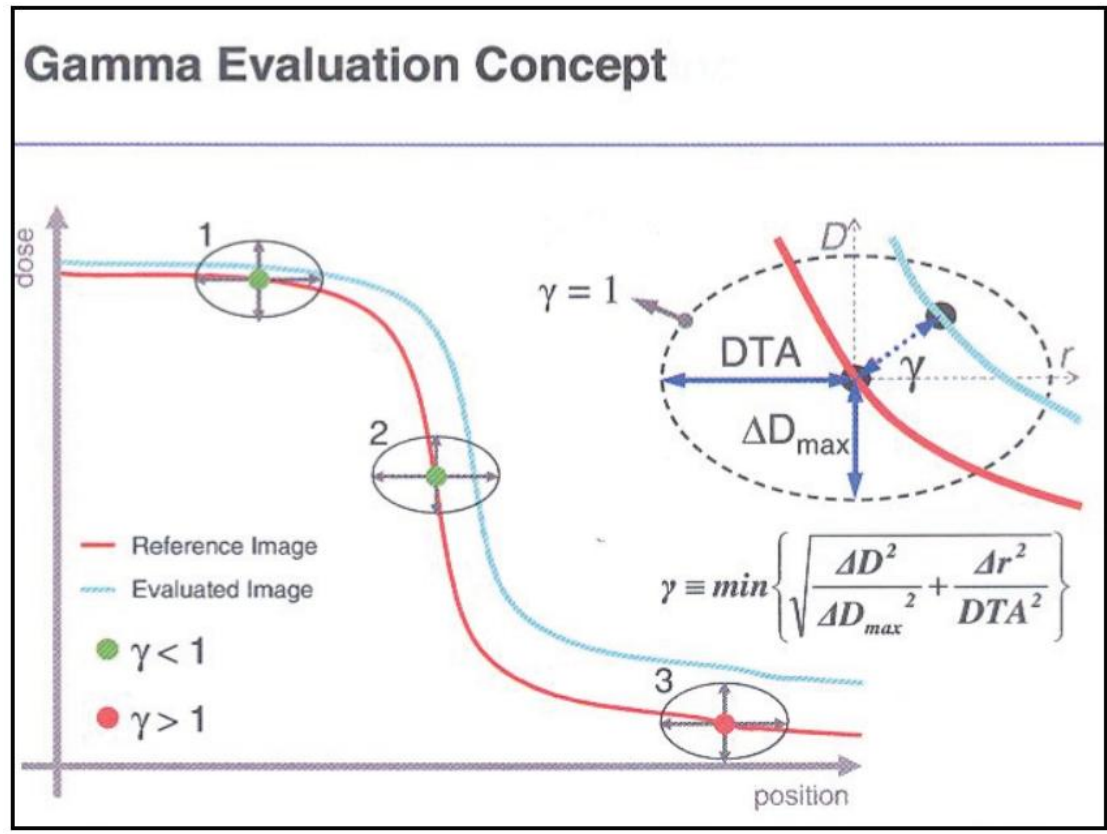

Figura 2.2 - Ilustração do conceito da função gama. A curva vermelha representa a imagem de referência e a azul, a imagem analisada - Fonte: Varian Medical Systems, Reference Guide for Portal Dosimetry

Além do comissionamento que é realizado antes de iniciar-se o tratamento dos pacientes é necessário continuar fazendo vários testes de checagem ao longo do tempo. Estes testes fazem parte de um programa de controle da qualidade e Dosimetria. Um adequado controle da qualidade na unidade de tratamento verifica a precisão mecânica e a dosimétrica do aparelho. O programa garante que a unidade esteja em conformidade com as recomendações do fabricante e as tolerâncias especificadas nos requisitos clínicos aplicáveis. A aplicação de testes mais importantes garante o perfeito alinhamento do feixe e garantem a precisão da dose, visando uma correta irradiação dos tecidos alvos $(26,47)$.

Existem vários métodos apropriados para estabelecer critérios de aceite no comissionamento de um sistema de planejamento(54) o critério de aceite de Venselaar é baseado na comparação entre a dose medida e a calculada pelo TPS.(55) Este critério utiliza da diferença percentual dada pela equação:

$$
\delta=100 \% \times\left(D_{\text {calo }}-D_{\text {Medido }}\right) / D_{\text {Medido }}
$$


Onde ${ }^{\delta}$ esta em porcentagem, ${ }^{D_{\text {Cale }}}$ é a dose calculada em um ponto do objeto

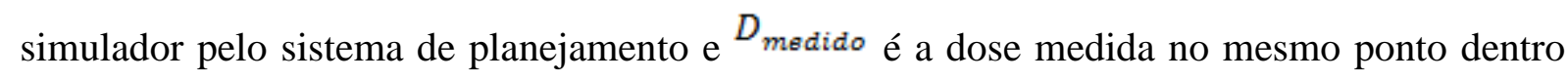
do objeto simulador.

Venselaar e colaboradores [67] definiram um conjunto de critérios de aceitabilidade com base em diferentes tolerâncias para $\delta$, A figura 2.3 apresenta regiões de interesse e a figura 2.4 os critérios.

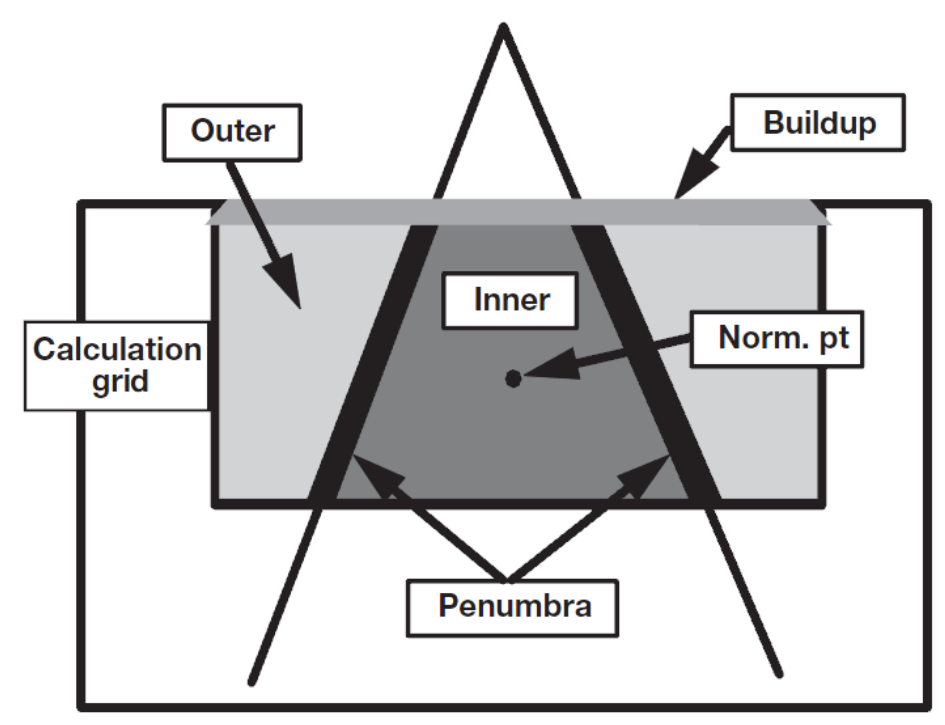

Figura 2.3 - Regiões que Venselaar utilizou para diferenciar os cretérios de tolerancia para aceitabilidade das dosimetrias de referências. Fonte TRS - 430. (49) 


\begin{tabular}{|c|c|c|c|c|c|}
\hline & Location & Type of region & $\begin{array}{c}\text { 1. Simple } \\
\text { geometry } \\
\text { (homogeneous) }\end{array}$ & $\begin{array}{l}\text { 2. Complex } \\
\text { geometry } \\
\text { (wedge, } \\
\text { inhomogeneity, } \\
\text { asymmetry) }\end{array}$ & $\begin{array}{l}\text { More complex } \\
\text { geometry } \\
\text { (combinations } \\
\text { of } 1 \text { and } 2 \text { ) }\end{array}$ \\
\hline$\delta_{1}$ & $\begin{array}{l}\text { Central beam } \\
\text { axis }\end{array}$ & $\begin{array}{l}\text { High dose, } \\
\text { small dose } \\
\text { gradient }\end{array}$ & $2 \%$ & $3 \%$ & $4 \%$ \\
\hline$\delta_{2}{ }^{a}$ & $\begin{array}{l}\text { Buildup region } \\
\text { of central axis } \\
\text { and penumbra } \\
\text { region of } \\
\text { profiles }\end{array}$ & $\begin{array}{l}\text { High dose, } \\
\text { large dose } \\
\text { gradient }\end{array}$ & $2 \mathrm{~mm}$ or $10 \%$ & $3 \mathrm{~mm}$ or $15 \%$ & $3 \mathrm{~mm}$ or $15 \%$ \\
\hline$\delta_{3}$ & $\begin{array}{l}\text { Outside central } \\
\text { beam axis } \\
\text { region }\end{array}$ & $\begin{array}{l}\text { High dose, } \\
\text { small dose } \\
\text { gradient }\end{array}$ & $3 \%$ & $3 \%$ & $4 \%$ \\
\hline$\delta_{4}$ & $\begin{array}{l}\text { Outside beam } \\
\text { edges }\end{array}$ & $\begin{array}{l}\text { Low dose, } \\
\text { small dose } \\
\text { gradient }\end{array}$ & $3 \%^{b}(30 \%)$ & $4 \%^{b}(40 \%)$ & $5 \%{ }^{\mathrm{b}}(50 \%)$ \\
\hline $\mathrm{RW}_{50}{ }^{\mathrm{a}}$ & $\begin{array}{l}\text { Radiological } \\
\text { width }\end{array}$ & & $2 \mathrm{~mm}$ or $1 \%$ & $2 \mathrm{~mm}$ or $1 \%$ & $2 \mathrm{~mm}$ or $1 \%$ \\
\hline$\delta_{50-90}$ & Beam fringe & & $2 \mathrm{~mm}$ & $3 \mathrm{~mm}$ & $3 \mathrm{~mm}$ \\
\hline
\end{tabular}

${ }^{a}$ These values are preferably expressed in $\mathrm{mm}$. A shift of $1 \mathrm{~mm}$ corresponding to a dose variation of $5 \%$ is assumed to be a realistic value in the high dose, large dose gradient region.

b This percentage is applicable to the following equation, $\delta_{4}=100 \% \times\left(D_{\text {calc }}-D_{\text {meas }}\right) /$ $D_{\text {meas,cax }}$, where $D_{\text {meas,cax }}$ is the dose on the central beam axis, since it is not always practicable to compare with the local dose. The values in brackets are those determined from Eq. (6).

Figura 2.4 - Critérios descritos por Venselaar em varias localizações de medidas do feixe no objeto simulador. Fonte TRS - 430.(49)

$\mathrm{Na}$ apresentação dos dados, Venselaar usou o limite de confiança $\Delta$. O limite de confiança é baseado no calculo do desvio médio entre a dose calculada e a medida para um grupo de pontos que apresentam situações semelhantes e o desvio padrão das diferenças, como na equação abaixo:

$$
\Delta=\mid \text { Desvio Médio } \mid+1,5 \times \text { Desvio Padrão }
$$

De acordo com o TG - 53 da $\operatorname{AAPM(56)~os~critérios~da~tabela~} 2.4$ são apenas exemplos do tipo de variação que é esperado para um sistema de planejamento com algoritmo 
sofisticado, isto é, eles não devem ser usados como meta ou requisitos para as instituições. Neste sentido o físico médico de cada instituição deve avaliar cada situação e escolher o critério para ser aplicado em cada situação particular.

\subsection{DOSIMETRIA}

A dosimetria das radiações é a determinação de uma grandeza dosimétrica depositada em um meio(57). Existem varias grandezas dosimétricas, entre elas estão à exposição, o kerma, e a dose absorvida. A grandeza dose absorvida, ou simplesmente dose, é uma grandeza que serve para descrever todos os tipos de radiação ionizante, incluindo partículas carregadas e não carregadas; todas as matérias e todas as energias. A dose absorvida é uma grandeza que reproduz melhor que as outras o efeito biológico causado por uma radiação ionizante.

Dose absorvida é definida como o quociente

$$
D=\frac{d E}{d M}
$$

Onde $d E$ é a energia média absorvida pela radiação ionizante em uma dada massa $d M$. A unidade antiga era o rad.

$$
1 \mathrm{rad}=10^{-2} \mathrm{~J} / \mathrm{kg}
$$

No SI a unidade da dose absorvida é o Gray, definida como:

$$
1 \mathrm{~Gy}=1 \mathrm{~J} / \mathrm{kg} \text {. }
$$

Desta forma:

$$
1 \mathrm{~Gy}=100 \mathrm{rad} \text {. }
$$

A fim de homogeneizar a maneira de adquirir a dose absorvida algumas instituições com renome internacional publicaram alguns protocolos para serem seguidos em dosimetrias clínicas. Os mais conhecidos são o TG-51 da Associação Americana de Física Médica (AAPM, do inglês American Association of Physicists in Medicine) e o TRS-398 da Agência Internacional de Energia Atômica (IAEA, do inglês International Atomic Energy Agency). Os 
dois protocolos foram desenvolvidos paralelamente e possuem um formalismo muito semelhante, ambos são baseados com a calibração da dose na água com câmara de ionização.

\subsubsection{Protocolo da IAEA TRS-398 para feixe de fótons de alta energia}

No protocolo TRS-398 a equação para determinação da dose absorvida em água quando a energia da calibração da câmara é diferente da energia do usuário é dada por:

$$
D_{w, Q}=M_{Q} N_{D, w, Q_{0}} k_{Q, Q_{0}}
$$

Onde $D_{w, Q}$ é a dose absolvida na água para o feixe do usuário, $N_{D, W_{2} Q_{0}}$ é o fator de calibração da câmara para o feixe de referência $\mathrm{Q}_{\mathrm{o}}$, geralmente o $\mathrm{Co}^{60}$, e $k_{Q_{Q_{0}}}$ é o fator que corrige a diferença de energia entre o feixe de referência $Q_{0}$ e o feixe do usuário $Q . M_{Q}$ é dado por:

$$
M_{Q}=M_{1} K_{T P} K_{p o l} K_{s}
$$

Onde $M_{1}$ é a leitura no dosímetro na tensão de referência $V_{1}, K_{T p}$ é o fator que corrige a diferença da leitura quando existe variação de temperatura e a pressão, dado pela equação:

$$
K_{T P}=\frac{P_{o}(273,2+T)}{P\left(273,2+T_{o}\right)}
$$

Onde $P$ e $T$ é a pressão e temperatura do usuário, enquanto $P_{o}$ e $T_{o}$ as de referência. $K_{\text {pol }}$ é o fator que corrige a polaridade da câmara:

$$
K_{p o l}=\frac{\left|M_{+}\right|+\left|M_{-}\right|}{2 M}
$$

Onde $M_{+}$é a leitura na polaridade positiva e $M_{-}$na polaridade negativa, $M$ é a leitura na polaridade de uso do usuário. O Fator $K_{g}$ corrige a recombinação iônica presente na câmara de ionização:

$$
K_{s}=\alpha_{0}+\alpha_{1}\left(V_{1} / V_{2}\right)+\alpha_{2}\left(M_{1} / M_{2}\right)^{2}
$$

Onde $\alpha_{0}, \alpha_{1}, \alpha_{2}$ são constates que depende do tipo de feixe. $V_{1}$ e $M_{1}$ é a tensão e a medida na condição 1, A tensão 2 deve ser no mínimo o dobro da tensão 2 (58). 


\subsubsection{Dosimetria in vivo}

A dosimetria in vivo tem como propósito verificar se a dose foi entregue na localização e intensidade correta. A dosimetria de referência no equipamento deve ser realizada periodicamente para garantir com precisão a liberação da radiação pelo aparelho, mas não garante que o sistema de planejamento calcule a dose adequadamente. Desta forma, uma dosimetria individual antes do tratamento é fundamental para confirmar o processo do planejamento. Por outro lado, isso ainda, não é suficiente para garantir a liberação da dose no momento da terapêutica. Logo, é de fundamental importância que seja realizada uma dosimetria no momento do tratamento, a qual é chamada de dosimetria in vivo(59-62).

\subsection{DOSÍMETROS}

Os dosímetros são dispositivos capazes de fornecer uma leitura, que permite determinar a dose, quando seu volume sensível recebe uma radiação ionizante.(57) Logo, para assegurar o rigor do comissionamento e dos testes de controle da qualidade é importante ter vários dosímetros que consigam se adequar ao tipo de medida necessária para cada finalidade (18). Dosímetro Termoluminescente (TLD), (do inglês Thermoluminescent Dosimetry), gel dosimétrico, filmes dosimétricos, câmara de ionização e matriz bidimensional de detectores são alguns dos mais usados.

Câmara de ionização é um detector capaz de coletar, em seu volume sensível, os íons gerados por uma radiação ionizante. Estes íons coletados no volume sensível da câmara são transferidos para um eletrômetro que quantifica este sinal. O sistema dosimétrico é o conjunto formado pela câmara de ionização e o eletrômetro. Este sistema é um dos mais usados para determinar medidas precisas como as que são exigidas em radioterapia, estando consagrado em utilizações clínicas e devido a isto, é normalmente escolhido como instrumento padrão.

Existem vários tipos de câmara de ionização, depende do fabricante, do modelo, e principalmente do seu volume sensível. A produção de íons depende diretamente do volume sensível da câmara, quanto maior é o volume maior será o sinal produzido. Porém a resolução espacial diminui com o aumento do volume, quanto menor for o volume sensível menor será 
o sinal. Logo, a câmara de ionização é um ótimo dosímetro que, normalmente, é utilizada na clínica, pois tem uma boa precisão e pode ser utilizada até para dosimetria padrão. Seu problema é que diminui o sinal quando se reduz seu volume (18).

Os filmes convencionais são muito utilizados em dosimetrias clínicas, a sua principal vantagem é a alta resolução espacial. O filme convencional é formado basicamente de duas partes: a base e a emulsão. A base é responsável por proporcionar uma estrutura rígida para que a emulsão possa ser fixada. A emulsão é uma mistura de gelatina e cristais de haleto de prata que a radiação ao interagir possibilita a transferência da informação.

A radiação que incide sobre o filme convencional deposita energia, primeiramente, na emulsão nos átomos dos cristais de haleto de prata, formando a imagem latente. Esta imagem não é visível porque é uma mudança microscópica nos cristais de haleto de prata. Com um processamento químico próprio, que é a revelação do filme, a imagem latente é convertida em imagem visível. Na processadora, o filme, após ser irradiado, passa por quatro estágios para a conversão da imagem latente em imagem visível: revelação, fixação, lavagem e secagem(21).

Nos filmes convencionais o controle dosimétrico pode ser prejudicado por uma contaminação química ou por uma variação indesejada da temperatura no momento da revelação, esta situação pode ser contornada utilizando filme radiocrômico, pelo fato deste filme não precisar de processamento químico para visualização da imagem.

O uso dos filmes radiocrômicos para dosimetria de radiações apareceu na década de 1960. Com a recente melhoria na tecnologia associada à produção desses filmes, seu uso tornou-se cada vez mais popular, especialmente na dosimetria braquiterápica. As principais vantagens dos filmes radiocrômicos incluem a equivalência de sua densidade com a água, a alta resolução espacial, o adequado intervalo de linearidade de dose para apliações em procedimentos de controle da qualidade em radioterapia, baixa dependência energética, insensibilidade à luz visível, e a não necessidade de revelação(63).

O filme radiocrômico possui número atômico efetivo equivalente ao da água $(\mathrm{Z}$ de 6 a $6,5)$ e sua densidade ótica estabiliza em torno de 24 horas após a irradiação. Sua dependência energética é menor que os filmes convencionais, são insensíveis à luz visível, mas necessita ficar em lugar escuro, além do que a temperatura deve ser controlada, pois apresenta sensibilidade à alta temperatura, como também à luz ultravioleta. Por este motivo, não deve permanecer muito tempo exposto à luz fluorescente e nem deve ser exposto ao sol (16). Outra 
preocupação com este tipo de filme é quanto a sua digitalização, pois ele tem dependência direcional na digitalização, desta forma ele deve sempre ser digitalizado na mesma direção a fim de conseguir melhor resultado nas atividades dosimétricas(64-67).

Os filmes radiocrômicos com emulsão EBT2 foram avaliados na verificação de dose para as diversas técnicas de radioterapia. Zeidan (2006) concluiu que existem diversas características favoráveis que permitam sua utilização na rotina de controle da qualidade em $\operatorname{IMRT}(68)$.

Wilcox e Daskalov (2007) avaliaram o filme gafchromic EBT para dosimetria e caracterização da radiocirurgia por CyberKnife®. Avaliaram as características peculiares de campos pequenos e altos gradientes de dose comparando com outros dosímetros, diodo e câmaras de ionização, e concluíram que para campos maiores que $10 \mathrm{~mm}$ o filme gafchromic produz medidas semelhantes aos outros dosímetros. Para campos menores que $10 \mathrm{~mm}$, devido principalmente ao equilíbrio eletrônico lateral e alcance máximo dos elétrons secundários, houve grande perda de sensibilidade na dose medida pela câmara de ionização e diodo. Os mesmos autores investigaram, em outro estudo, a precisão das medidas de dose e comparação dos cálculos por Monte Carlos dentro e fora para tecidos heterogêneos por 6 campos de fótons menores que $4 \mathrm{~cm}$ em radiocirurgia por CyberKnife®. Concluíram que o filme gafchromic EBT é dosímetro adequado para medir a dose em materiais heterogêneos $(69,70)$.

Mehta e colaboradores (2010) em estudos de dosimetria e controle da qualidade em irradiadores de animais utilizou para seus estudos segmentos de filme radiocrômicos com dimensões de $2,5 \times 2,5 \mathrm{~cm}^{2}$ e concluiu que o filme radiocrômico segmentado pode ser utilizado para dosimetria relativa através da medição das densidades óticas(71).

O Matrixx é uma matriz bidimensional constituída de várias câmaras de ionização capaz de fornecer uma medida de dose em um plano. Em 2008 McCurdy e colaboradores testaram o Matrixx da IBA acoplado no cabeçote do aparelho para realização do controle da qualidade em IMRT (72). Esta configuração apresentou-se bastante adequada por não apresentar dependência angular e ainda poder ser utilizada por vários campos em diversas angulações, mas o Matrixx não se mostrou adequado para medidas de dosimetria in vivo porque apresentava baixa resolução espacial, além de absorver muita radiação. 
Capítulo 3 - Materiais e Métodos 


\section{MATERIAIS E MÉTODOS}

A base da técnica da dosimetria in vivo foi acoplar o segmento de filme radiocrômico no cabeçote do AL, no eixo central, a ideia é determinar qual a densidade relativa (DR) que o filme deverá adquirir após o tratamento radioterápico se o filme estiver na posição descrita anteriormente. Para isso, realizou-se uma calibração que relacionava o número de unidades monitoras com a densidade relativa para um campo de 50x50 $\mathrm{mm}^{2}$. Realizaram-se exposições de 0 a 380 UM e mediu-se a densidade relativa a fim de ter uma relação de UM versus DR. Desta forma, após o termino do planejamento é possível somar o número total de unidades monitoras e relacionar com a densidade relativa que o filme deverá adquirir se o campo equivalente médio for de $50 \mathrm{~mm}$. Porém, em geral os campos equivalentes médios não vão coincidir com $50 \mathrm{~mm}$, logo, foi realizado um estudo da variação da densidade relativa com relação ao tamanho de campo, para isso, os filmes foram expostos com $100 \mathrm{UM}$ em diversos tamanhos de campos e depois avaliou-se a densidade relativa. $\mathrm{O}$ valor de cada densidade relativa foi dividido pela densidade relativa do filme que foi irradiado com campo de 50x50 $\mathrm{mm}^{2}$, ou seja, normalizou-se no campo de $50 \times 50 \mathrm{~mm}^{2}$ porque a calibração foi executada neste tamanho de campo.

Como a técnica de dosimetria in vivo utiliza os dados provenientes do TPS, confirmou-se alguns parâmetros do comissionamento do TPS a fim de garantirmos a credibilidade na técnica. Depois do comissionamento do TPS e do desenvolvimento da técnica de dosimetria in vivo, validou-se a técnica de dosimetria in vivo com um controle da qualidade convencional. No controle da qualidade convencional realizou-se dosimetria pontual de referência com câmara de ionização posicionada dentro de um objeto simulador no isocentro, e acima da câmara foi colocado um filme com dimensões de $15 \times 20 \mathrm{~cm}^{2}$ para avaliação bidimensional em um plano coronal dentro do objeto simulador. Neste momento foi posicionado o segmento de filme radiocrômico $1 \times 1 \mathrm{~cm}^{2}$ no cabeçote do AL para avaliação da técnica de dosimetria in vivo, e um filme $15 \times 12 \mathrm{~cm}^{2}$ para avaliação da dose em duas dimensões dentro do objeto simulador, além da câmara de ionização para a avaliação da dose de referência no centro do objeto simulador.

Neste capítulo são apresentados os materiais utilizados e os métodos empregados para o comissionamento do sistema de planejamento, para o desenvolvimento da técnica de dosimetria in vivo e para a avaliação da técnica em cinco planos. Este capítulo foi dividido em 
cinco sessões: a primeira descreve os objetos simuladores utilizados neste trabalho, a segunda os dosímetros utilizados, a terceira apresenta os testes realizados na avaliação de alguns parâmetros relativos ao comissionamento do TPS, a quarta o desenvolvimento da técnica de dosimetria in vivo e a quinta a avaliação da técnica.

Todas as irradiações foram realizadas no Acelerador Linear Oncor, marca Siemens, com feixe de 6 MV, do Hospital das Clínicas da Faculdade de Medicina de Ribeirão Preto da Universidade de São Paulo (HCFMRP-USP). O sistema de planejamento avaliado no estudo é o iPlan, marca BrainLab, com algoritmo de cálculo de dose pencil beam, este sistema é específico para simular planos de radioterapia estereotáxica.

O colimador com micro-lâminas empregado foi o Moduleaf com 80 lâminas, marca Siemens, que possui $2,5 \mathrm{~mm}$ de espessura no isocentro e, desta forma é considerado próprio para a realização de radiocirurgia e radioterapia estereotáxica, pois é capaz de conformar as formas irregulares das lesões, minimizando a irradiação de órgãos de risco.

\subsection{OBJETOS SIMULADORES}

Neste trabalho foram utilizadas várias combinações diferentes de placas de água sólida, placas de alumínio, placas de cortiça, além de um objeto simulador cúbico de água sólida. As 20 placas de água sólida possuíam dimensões de 30 × 30 x $1 \mathrm{~cm}^{3}$ e densidade de 1 $\mathrm{g} / \mathrm{cm}^{3}$, as 8 placas de alumínio apresentavam dimensões de $30 \times 30 \times 1 \mathrm{~cm}^{3}$ e densidade de 2,7 $\mathrm{g} / \mathrm{cm}^{3}$ e as 30 placas de cortiça tinham aproximadamente dimensões de 30 x 30 x 0,2 $\mathrm{cm}^{3}$ e densidade de $0,32 \mathrm{~g} / \mathrm{cm}^{3}$. O Objeto simulador cúbico de água sólida apresentava as dimensões de 18 x $18 \times 18 \mathrm{~cm}^{3}$, como mostra a figura 3.1 .

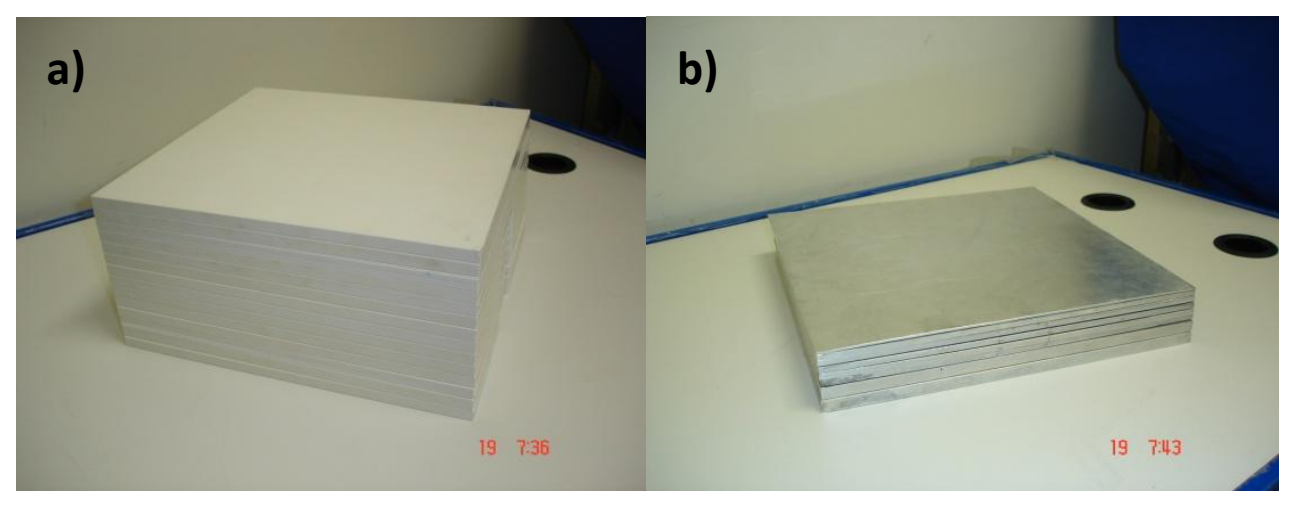




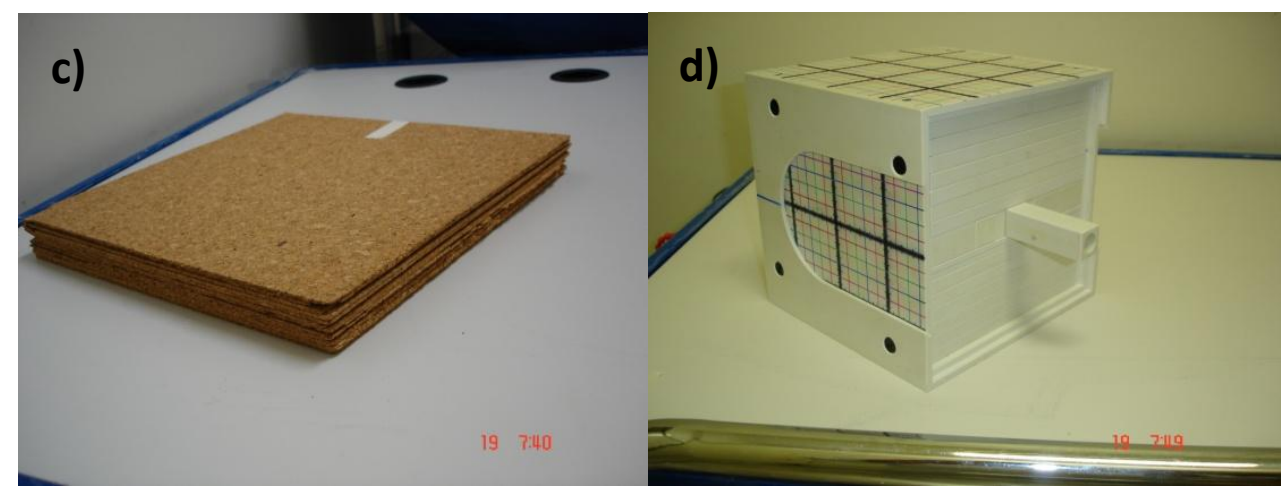

Figura 3.1 - Objetos simuladores: a) água sólida, b) alumínio, c) cortiça, d) objeto simulador cúbico de água sólida.

\subsection{DOSÍMETROS}

Para medição da radiação foram usados dois tipos dosímetros: câmara de ionização e filme radiocrômico.

\subsubsection{Câmara de ionização e eletrômetro}

O conjunto formado pela câmara de ionização e o eletrômetro foi usada para determinar a dosimetria de referência no comissionamento, no desenvolvimento da técnica de dosimetria in vivo e na validação da técnica. Em todos os casos foram utilizados o mesmo eletrômetro Dose1 da marca IBA e a mesma câmara de ionização CC13 de volume sensível de $0,13 \mathrm{~cm}^{3}$ da marca IBA, como mostra a figura 3.2 .

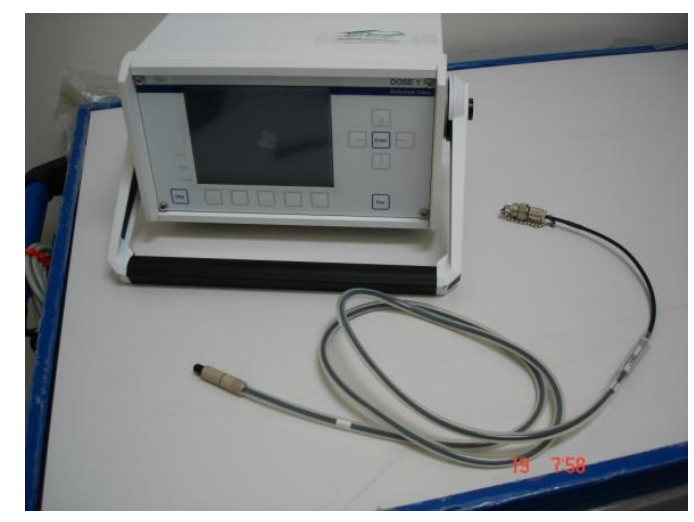

Figura 3.2 - Conjunto dosimétrico, eletrômetro Dose1 e câmara de ionização CC13. 


\subsubsection{Filme Radiocrômico}

O filme radiocrômico Gafchromic EBT2 possui densidade eletrônica aproximada de 1,3 $\mathrm{g} / \mathrm{cm}^{3}$, número atômico efetivo próximo ao da água de 6,84 , resolução espacial de $100 \mu \mathrm{m}$, dependência energética menor que $10 \%$ para um intervalo de $60 \mathrm{kV}$ até MV e intervalo de ação de 0 a 40 Gy(73). Para as analises das doses em duas dimensões nos controles da qualidade convencionais foi realizada uma calibração no filme com auxilio de um objeto simulador de água sólida na profundidade de máxima dose de $1,5 \mathrm{~cm}$, para o feixe de fótons de $6 \mathrm{MV}$, e mais $10 \mathrm{~cm}$ de água sólida sob o filme para garantir o retro-espalhamento necessário e utilizando a configuração com SSD de $100 \mathrm{~cm}$. O filme foi irradiado com doses de 0 a 15 Gy com intervalo de 0,5 Gy.

O filme Gafchromic EBT2 foi usado para o desenvolvimento da técnica de dosimetria e para o controle da qualidade convencional na validação da técnica de dosimetria in vivo.

\subsection{COMISSONAMENTO DO TPS}

$\mathrm{Na}$ verificação de alguns dados do sistema de planejamento com os dados reais do acelerador linear, o comissionamento do TPS foi dividido em duas avaliações: avaliação da dose pontual com mMLC em campos circulares e medição da dose pontual em objetos simuladores heterogêneos com mMLC.

No comissionamento foi avaliado o cálculo da dose do TPS com os diferentes tamanhos de campos através de dosimetria de referência. E por ultimo, foi analisado o cálculo da correção de heterogeneidade do TPS, para objetos simuladores com materiais heterogêneos de baixa e alta densidade com câmara de ionização. 


\subsubsection{Dosimetria de referência em campos diretos com mMLC}

Uma imagem de tomografia computadorizada do objeto simulador cúbico de água sólida foi adquirida para obtenção da dosimetria de referência, as dimensões do objeto simulador são $18 \times 18 \times 18 \mathrm{~cm}^{3}$. A simulação dos campos no TPS foi realizada com o gantry a zero grau e técnica isocêntrica, os feixes usados para dosimetria possuíam um formato circular em campos equivalentes de 30,6; 40,4; 50,3; 70,2 e 100 mm. A câmara de ionização, posicionada no centro do objeto simulador, foi usado para avaliação da dose de $1 \mathrm{~Gy}$.

As medidas foram realizadas em um acelerador linear com a câmara de ionização posicionada nas mesmas condições utilizadas na simulação. As medidas foram realizadas utilizando a câmara de ionização CC13 acoplada ao eletrômetro Dose1. Compararam-se as medidas realizadas na dosimetria de referência com os fornecidos pelo sistema de planejamento. A figura 3.3 mostra a configuração para a irradiação no Acelerador Linear para determinação da dosimetria de referência com o mMLC, onde se pode ver a câmara de ionização posicionada.

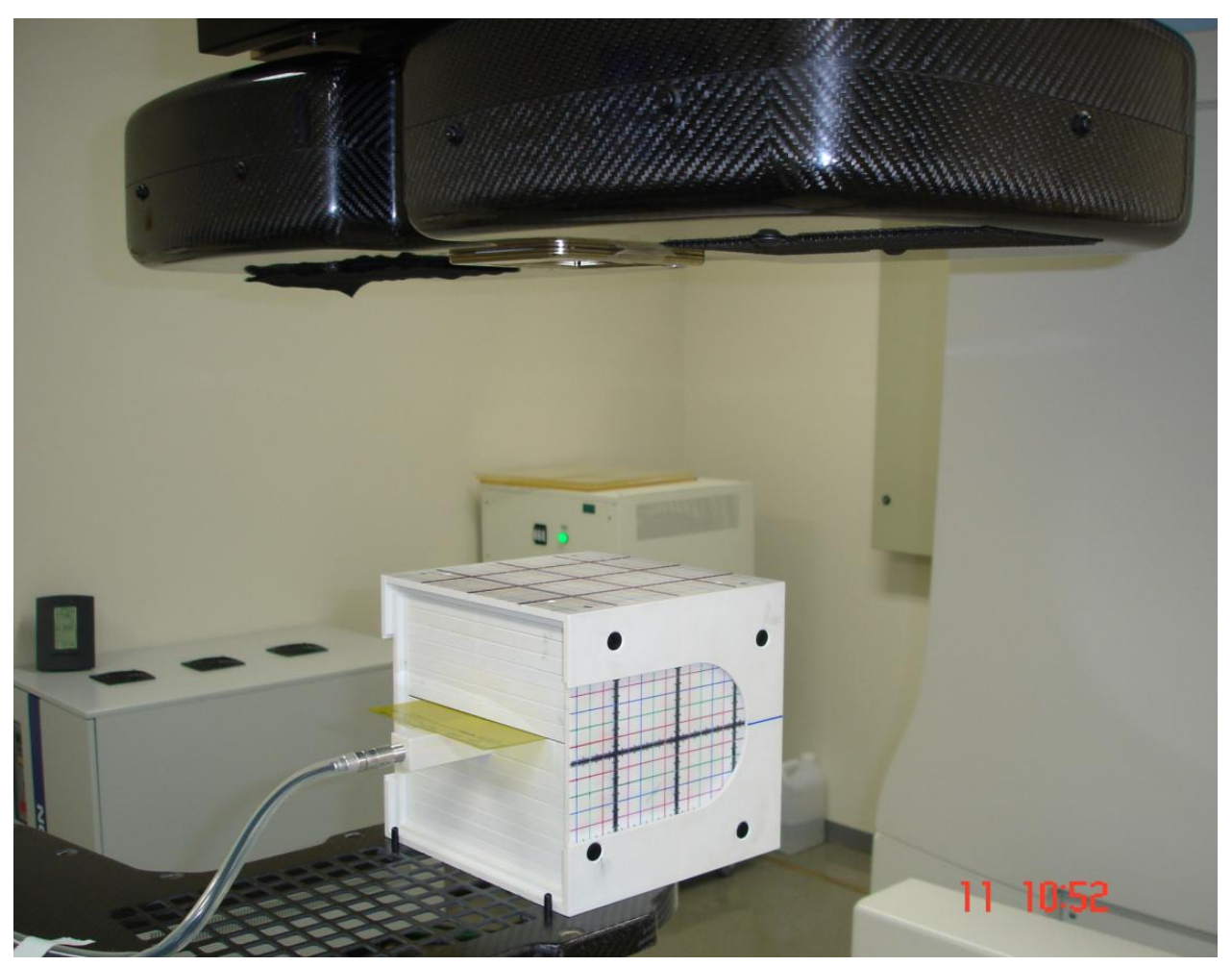

Figura 3.3 - Configuração das irradiações para dosimetria de referência com mMLC. 


\subsubsection{Dosimetria de referência em objetos simuladores heterogêneos com mMLC}

A partir de imagens adquiridas em CT foram simulados no TPS quatro planos com feixe único, com gantry a zero grau, e utilizando a correção de heterogeneidade, em campos $20 \times 20,30 \times 30,50 \times 50$ e $100 \times 100 \mathrm{~mm}^{2}$ com feixe de $6 \mathrm{MV}$ e $100 \mathrm{UM}$. Em seguida, todas as duas configurações de objetos simuladores foram irradiadas no acelerador linear com mMLC, e comparadas com os valores adquiridos pelo TPS.

A primeira configuração foi formada com água sólida e cortiça, sendo que a cortiça tendo densidade bem mais baixa simula as cavidades de ar presentes no organismo humano, como seios da face. O objeto simulador era constituído por quatro centímetros de água sólida, três de cortiça e três de água sólida antes da câmara de ionização, respectivamente. Abaixo da câmara foram colocados mais seis centímetros de água sólida, responsável pelo retro espalhamento, como mostra a figura 3.4. A espessura de $3 \mathrm{~cm}$ da cortiça é maior que os valores encontrados na face humana, porem foi realizado uma espessura maior a fim de ter um maior efeito da baixa heterogeneidade na avaliação da dose.

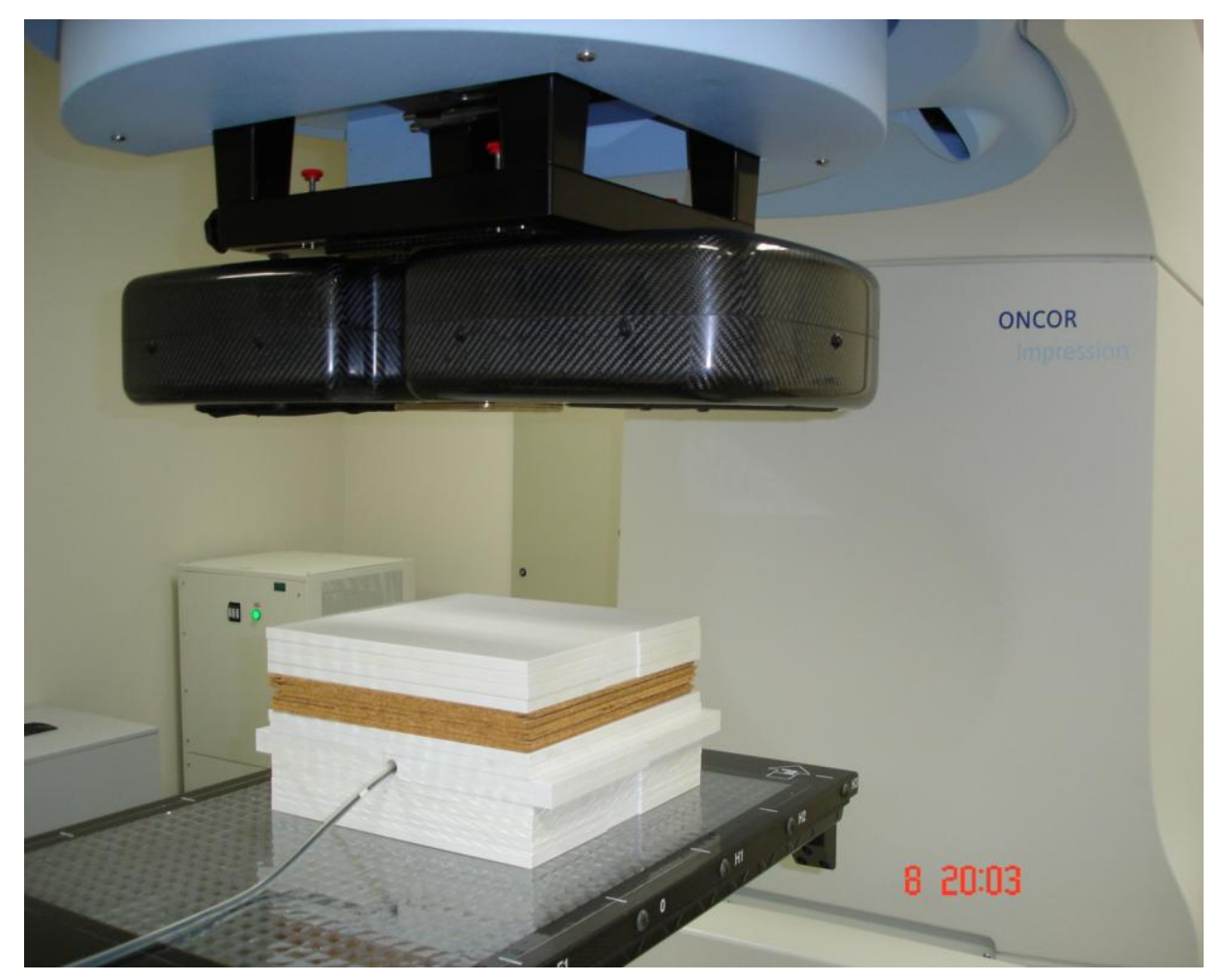

Figura 3.4

Figura 3.4 - Configuração para a determinação da dose de referência com objeto simulador constituído por água sólida e cortiça. 
A segunda configuração foi formada com água sólida e alumínio, a qual por ter densidade mais alta, simula as regiões mais densas, presentes no organismo humano, como os ossos. Nesta configuração, como mostra a figura 3.5, o objeto simulador possuía quatro centímetros de água sólida, três de alumínio e mais três de água sólida antes da câmara de ionização, e para simular a radiação retro espalhada foi colocado abaixo da câmara mais seis centímetros de água sólida. A espessura de $3 \mathrm{~cm}$ do alumínio é maior que as espessuras do osso encontradas na face humana, porém foi realizado uma espessura maior a fim de ter um maior efeito da alta heterogeneidade na avaliação da dose.

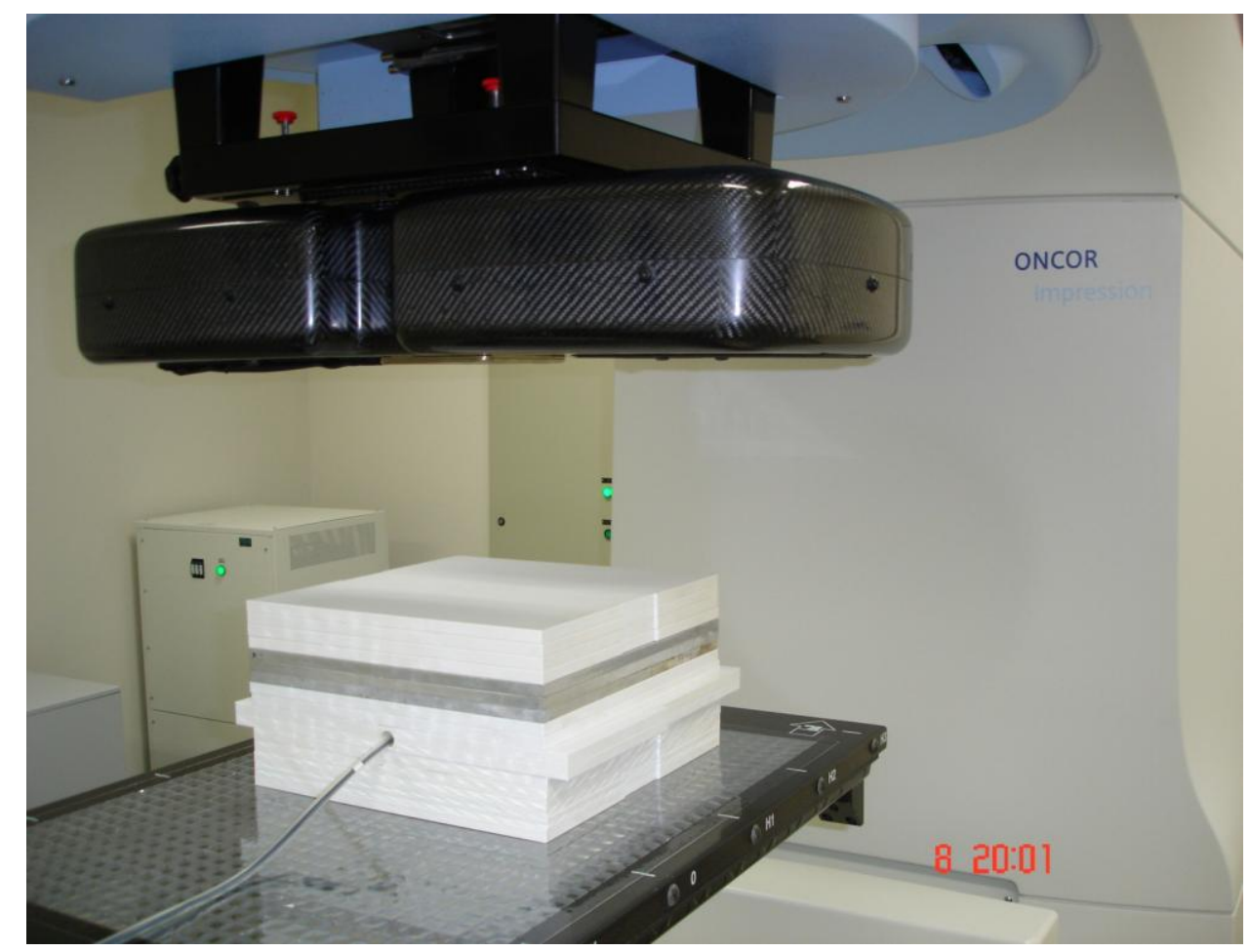

Figura 3.5- Configuração para a determinação da dose de referência com o objeto simulador constituído de água sólida e alumínio.

\subsection{DESENVOLVIMENTO DA TÉCNICA DE DOSIMETRIA IN VIVO}

A técnica para dosimetria in vivo foi formada por segmentos de filmes radiocrômicos, nas dimensões de $1 \times 1 \mathrm{~cm}^{2}$, envolvidos em pedaços de papel. O papel foi empregado para 
proteger o filme da fita colante usada para acoplar os segmentos no cabeçote do acelerador linear. Estas amostras foram acopladas na área externa ao colimador mMLC e inseridos na região do eixo central do feixe, como mostra a figura 3.6.

As analises dos filmes foram realizadas 24 horas depois da irradiação, os filmes foram armazenados sem presença de luz e na temperatura de $22{ }^{\circ} \mathrm{C}$. As densidades relativas dos filmes foram adquiridas pelo densitômetro digital CQ-01 da MRA. A fim de avaliar a reprodutibilidade dos segmentos de filme radiocrômicos foram realizadas cinco exposições com 100 UM e cinco com 300 UM na configuração da técnica de dosimetria in vivo com o campo de $50 \times 50 \mathrm{~mm}^{2}$.

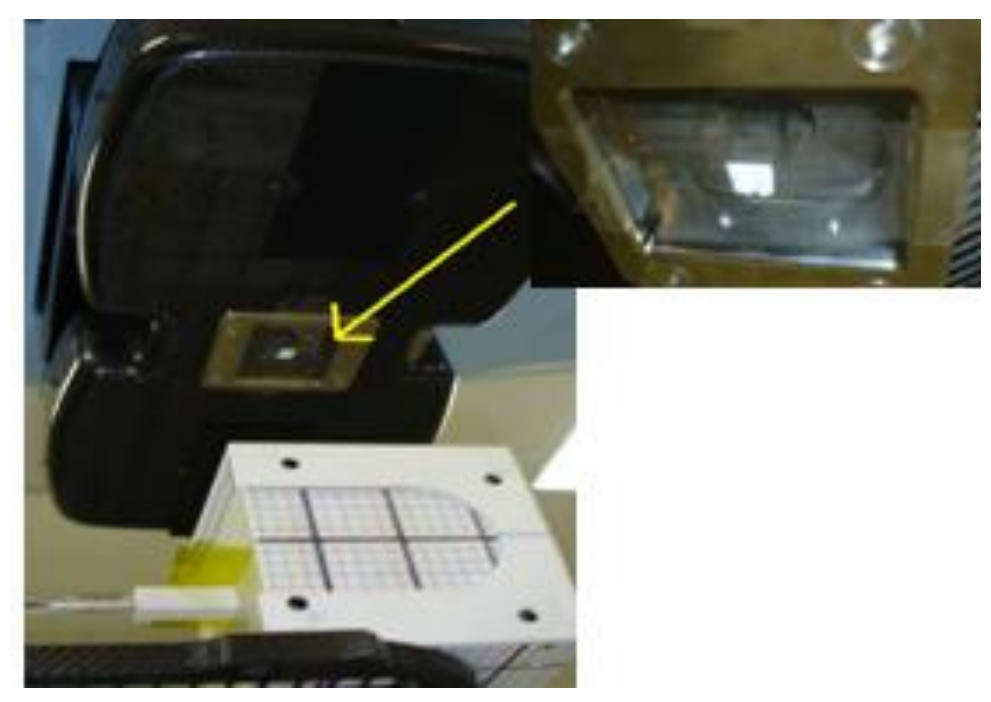

Figura 3.6

Figura 3.6 - Configuração utilizada na irradiação dos segmentos de filmes. No detalhe o filme posicionado no eixo central da saída do feixe.

Durante a calibração os filmes foram expostos de 0 a 380 unidades monitoras com intervalos de $20 \mathrm{MU}$ em campos de 50 x $50 \mathrm{~mm}^{2}$. Entretanto, para dependência dosimétrica da dimensão do campo (DDDC), os segmentos foram expostos com $100 \mathrm{MU}$ nas dimensões de $10 \times 10,20 \times 20,30 \times 30,50 \times 50,70 \times 70,100 \times 100 \mathrm{~mm}^{2}$. As densidades relativas (DR) de todos os filmes foram medidas utilizando um densitômetro ótico.

Com os dados da DR elaborou-se uma planilha para calcular a densidade relativa que um filme deve adquirir quando submetido a uma exposição com esta configuração. A planilha em Excel calcula o campo equivalente médio de todos os feixes envolvidos no processo, as 
somas das unidades monitoras de todos os campos e relaciona estes dados, com os da calibração do filme e DDDC.

\subsection{AVALIAÇÃO DA TÉCNICA DE DOSIMETRIA IN VIVO EM CINCO PLANOS}

Para validação do processo foram estudados cinco planos não co-planares produzidos no TPS simulando alguns tratamentos padrões utilizados em radioterapia estereotáxica no HCFMRP, sendo o primeiro com campo equivalente médio de $51 \mathrm{~mm}$ em 15 campos e os outros quatro planos, em 25 campos, com campos equivalentes médios de 22; 28; 38; e 53 mm. Os dados dos planos usados nesta validação são apresentados nas tabelas do apêndice.

$\mathrm{Na}$ avaliação da técnica de dosimetria in vivo em cinco planos foram comparadas as densidades relativas calculada na planilha desenvolvida com os dados medidos após a execução da irradiação, e para validação da técnica da dosimetria in vivo, foram realizadas os controles da qualidade convencionais no objeto simulador cúbico de água sólida. Nesta analise, realizou-se um controle da qualidade convencional com câmara de ionização e filme radiocrômico. A câmara de ionização, $\mathrm{CC} 13$, foi posicionada no centro do objeto simulador e o filme radiocrômico localizado a um centímetro acima do centro, como mostra a figura 3.7. 


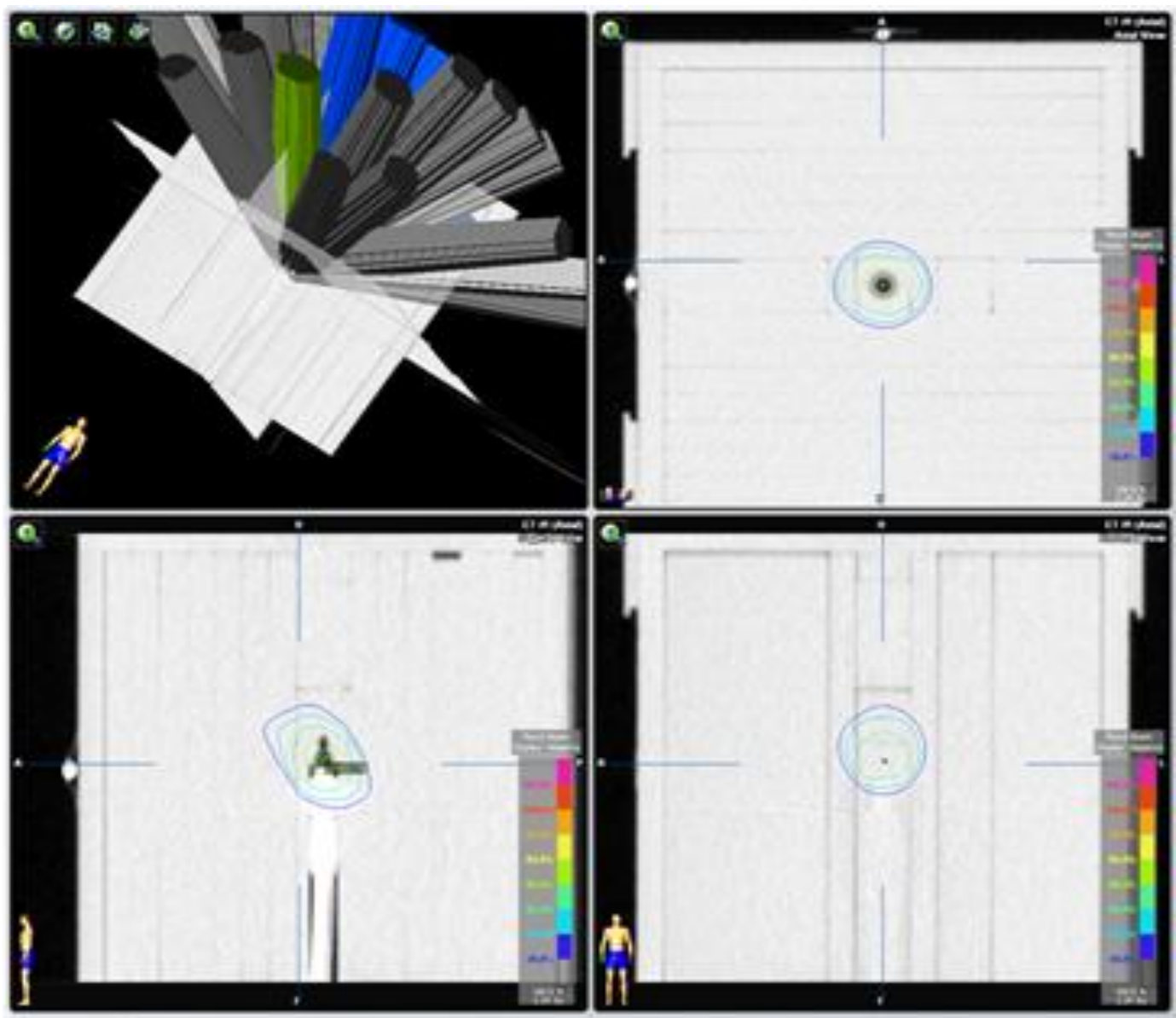

Figura 3.7 - Exemplo de um plano com 25 campos realizado em TPS. Em destaque esta a imagem do CT do objeto simulador com a câmara posicionada no centro. O filme esta posicionado na convergência das linhas azuis a $1 \mathrm{~cm}$ acima da câmara.

As analises dos filmes foram realizadas 24 horas depois da irradiação, os filmes ficaram dentro de uma caixa sem presença de luz e na temperatura de $22{ }^{\circ} \mathrm{C}$. As imagens foram digitalizadas considerando sempre a mesma posição do filme.

A função gama foi avaliada comparando a distribuição de dose no plano coronal dos dados do TPS com os dados adquiridos pelo filme, no software OmniPro, com critérios $\Delta \mathrm{r}=2$ $\mathrm{mm}$ e $\Delta \mathrm{D}=2 \%$. O ICRU e diversos trabalham admitem critérios maiores, porém critérios menores foram usados por causa das pequenas dimensões dos campos envolvidos em radioterapia estereotáxica(74-77) 
Capítulo 4 - Resultados e Discussões 


\section{RESULTADOS E DISCUSSÕES}

Neste capítulo são apresentados os resultados adquiridos no comissionamento do TPS, o desenvolvimento da técnica de dosimetria in vivo e a sua avaliação em cinco planos.

\subsection{COMISSIONAMENTO DO TPS}

Esta sessão foi subdividida em: dosimetria de referência em campos com mMLC e dosimetria de referência em objetos simuladores heterogêneos com mMLC.

\subsubsection{Dosimetria de referência em campos com mMLC}

A dosimetria de referência em campos com o mMLC foi determinada através de medidas realizadas com câmara de ionização tipo CC13 na profundidade de nove centímetros no objeto simulador de água sólida de dimensões de 18 x 18 x $18 \mathrm{~cm}^{3}$ e posteriormente comparadas com os dados coletados pelo TPS. Para avaliação da dose no centro da câmara foram simulados sete feixes circulares com campos equivalentes a 30,6; 40,4; 50,3; 70,2; e $100 \mathrm{~mm}$, no sistema de planejamento iPlan.

A tabela 4.1 apresenta as doses, em cGy, obtidas no TPS e na câmara de ionização, como também, as diferenças percentuais.

Tabela 4.1 - Comparação entre as dose adquiridas no sistema de planejamento e as doses aferidas com a câmara de ionização, nos campos circulares, para os campos equivalentes de 30,$6 ; 40,4 ; 50,3 ; 70,2$ e $100 \mathrm{~mm}$.

\begin{tabular}{ccccc}
\hline \hline Ceq $(\mathrm{mm})$ & Dose (cGy) & Dose Med.(cGy) & Desvio Padrão & Dif \% \\
30,6 & 100 & 100,33 & 0,01 & $-0,3$ \\
40,4 & 100 & 100,02 & 0,01 & 0,0 \\
50,3 & 100 & 100,10 & 0,01 & $-0,1$ \\
70,2 & 100 & 100,72 & 0,01 & $-0,7$ \\
100 & 100 & 99,73 & 0,02 & 0,3 \\
\hline \hline
\end{tabular}


Nota-se que os valores das diferenças percentuais estão abaixo de $2 \%$, logo em concordância com o limite estabelecido no TRS-430.(49)

\subsubsection{Dosimetria de referência em objetos simuladores heterogêneos com mMLC}

O cálculo adequado da dose com materiais heterogêneos é um fator importante que deve ser avaliado, pois muitos fatores podem contribuir com a imprecisão na distribuição da dose, onde um dos erros mais comum esta relacionado com o tipo de cálculo que o sistema possui, ou com a relação entre a densidade eletrônica que o TPS usa e o número de CT liberado pelo tomógrafo(78).

\subsubsection{Objeto simulador de água sólida e cortiça}

No TPS foram simulados cinco planos com dimensões de 30 × 30, 50 x 50 e 100 x 100 $\mathrm{mm}^{2}$, todos com exposições de 100 unidades monitoras para avaliação da dose no centro da câmara. As curvas de isodose obtidas pelo TPS, sem e com correção de heterogeneidade, para a somatória de todos os campos são apresentadas na figura 4.2. Pode-se observar na figura 4.2 que as curvas do item b penetram mais que as curvas do item a, isso é devido ao fato de não estar sendo considerada a baixa densidade da cortiça no cálculo do item a.

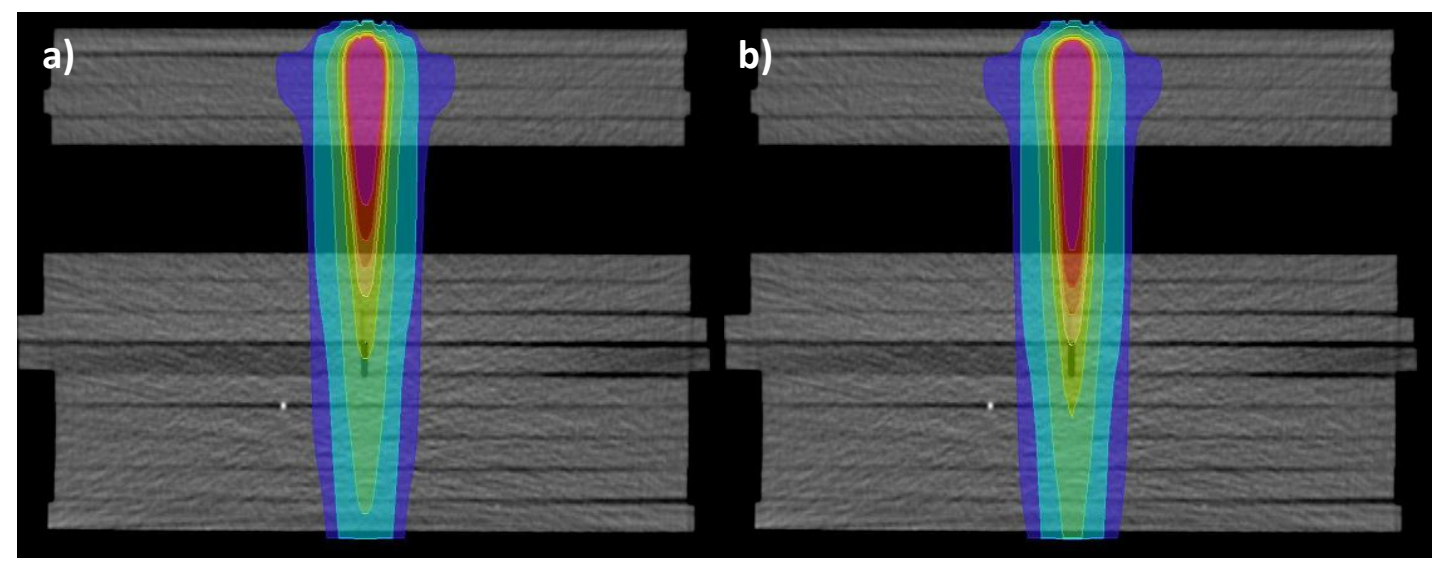

Figura 4.1 - Curvas de isodose fornecidas pelo TPS, com os campos 30 x 30, 50 x 50 e 100 x $100 \mathrm{~mm}^{2}$ habilitados simultaneamente no objeto simulador composto por água e cortiça. a) 
curvas de isodose sem aplicar a correção de heterogeneidade. b) curvas de isodose aplicando a correção de heterogeneidade.

As doses, em cGy, obtidas através do TPS, assim como as doses obtidas com a câmara de ionização e as diferenças percentuais são apresentadas na tabela 4.2, onde se nota que todas as diferenças percentuais estão de acordo com as recomendações do TRS - 430.(49)

Tabela 4.2 - Comparação entre as doses, em campos quadrados, adquiridas no sistema de planejamento e a câmara de ionização, no objeto simulador composto por água sólida e cortiça.

\section{Água Sólida e Cortiça}

\begin{tabular}{ccccc}
\hline \hline Campo $\left(\mathbf{m m}^{2}\right)$ & $\mathbf{D}_{\text {iPlan }}(\mathbf{c G y})$ & $\mathbf{D}_{\mathrm{cl}}$ (cGy) & Desvio Padrão & Dif (\%) \\
$30 \times 30$ & 72 & 72,99 & 0,08 & $-1,36$ \\
$50 \times 50$ & 77 & 78,03 & 0,02 & $-1,32$ \\
$100 \times 100$ & 86 & 86,97 & 0,05 & $-1,12$ \\
\hline \hline
\end{tabular}

\subsubsection{Objeto simulador de água sólida e alumínio}

No sistema de planejamento foram gerados quatro campos com dimensões de $20 \times 20$, $30 \times 30,50 \times 50$ e $100 \times 100 \mathrm{~mm}^{2}$ e expostos a 100 unidades monitoras. As curvas de isodose obtidas pelo TPS, sem e com correção de heterogeneidade, com a somatória de todos os campos são apresentadas na figura 4.4, onde se pode observar que as curvas de isodose do item a penetram mais que as curvas do item $\mathbf{b}$, isso se deve ao fato de que nas curvas do item a, não está sendo levada em conta, nos cálculos, a alta densidade do alumínio.

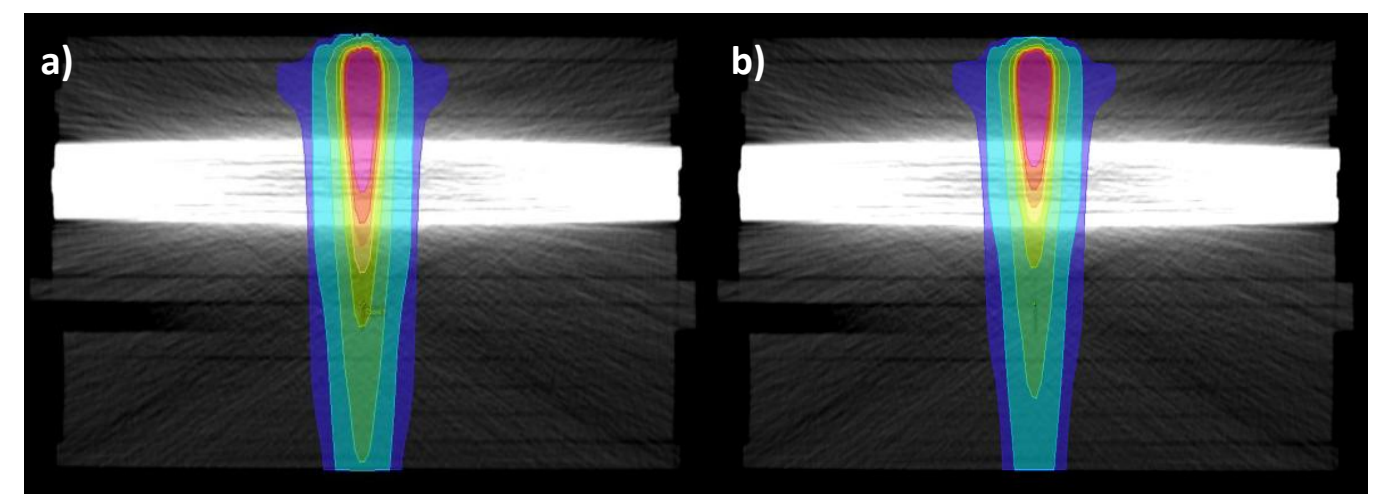


Figura 4.2 - Curvas de isodose, fornecidas pelo TPS, com os campos $20 \times 20,30$ x 30, 50 x 50 e $100 \times 100 \mathrm{~mm}^{2}$ habilitados simultaneamente no objeto simulador composto por água e alumínio. a) curvas de isodose sem aplicar a correção de heterogeneidade. b) curvas de isodose aplicando a correção de heterogeneidade.

As doses, em cGy, obtidas com o TPS, assim como as doses obtidas com a câmara de ionização e suas diferenças percentuais são apresentadas na tabela 4.3, onde se nota que todas as diferenças percentuais estão de acordo com as recomendações com o TRS - 430.(49)

Tabela 4.3 - Comparação entre as doses, em campos quadrados, adquiridas no TPS e a câmara de ionização posicionada no objeto simulador composto por água sólida e alumínio.

Água Sólida e Alumínio

\begin{tabular}{ccccc}
\hline \hline Campo $\left(\mathbf{m m}^{2}\right)$ & $\mathbf{D}_{\text {IPlan }}$ (cGy) & $\mathbf{D}_{\mathrm{cI}}(\mathrm{cGy})$ & Desvio Padrão & Dif (\%) \\
$30 \times 30$ & 58 & 57,96 & 0,07 & 0,07 \\
$50 \times 50$ & 63 & 63,99 & 0,02 & $-1,55$ \\
$100 \times 100$ & 72 & 72,97 & 0,04 & $-1,32$ \\
\hline \hline
\end{tabular}

Kairn e colaboradores, 2011, avaliou o algoritmo de calculo pencil bean e encontrou resultados não satisfatórios para as regiões com densidades eletrônicas diferentes da água. Porém sua metodologia, diferente deste estudo, avaliou a dose na região de densidade diferente, neste estudo o feixe atravessa por uma região de densidade eletrônica diferente mais a avaliação da dose é realizada na água sólida(79).

\subsection{DESENVOLVIMENTO DA TÉCNICA DE DOSIMETRIA IN VIVO}

Para o desenvolvimento da técnica de dosimetria in vivo foram realizadas exposições para avaliação da reprodutibilidade das leituras dos filmes, calibração dos filmes e o estudo da dependência dosimétrica da dimensão do campo (DDDC) na configuração especifica da técnica. 


\subsubsection{Reprodutibilidade}

A tabela 4.4 apresenta as densidades relativas dos filmes expostos a $100 \mathrm{UM}$ e 300 UM no campo de 50x50 $\mathrm{mm}^{2}$ na configuração da técnica de dosimetria in vivo. Observa-se que os filmes apresentaram boa reprodutibilidade já que apenas um dos filmes obteve densidade relativa diferente dos demais. DR1 é a primeira medida realizada no densitômetro ótico e DR2 a segunda medida do mesmo filme.

Tabela 4.4 - Densidade relativa dos filmes expostos a 100 UM e 300 UM na configuração da técnica de dosimetria in vivo.

\begin{tabular}{rrr}
\multicolumn{3}{c}{100 UM } \\
\hline & DR 1 & DR 2 \\
\hline Filme1 & 0,40 & 0,40 \\
Filme2 & 0,40 & 0,40 \\
Filme3 & 0,40 & 0,40 \\
Filme4 & 0,40 & 0,40 \\
Filme5 & 0,40 & 0,40 \\
\hline \hline
\end{tabular}

\begin{tabular}{rrr}
\hline \multicolumn{3}{c}{300 UM } \\
\hline & DR 1 & DR 2 \\
\hline Filme1 & 0,60 & 0,60 \\
Filme2 & 0,60 & 0,61 \\
Filme3 & 0,60 & 0,60 \\
Filme4 & 0,60 & 0,60 \\
Filme5 & 0,60 & 0,60 \\
\hline \hline
\end{tabular}

\subsubsection{Calibração dos filmes}

A figura 4.5 apresenta o gráfico das densidades relativas, em função das unidades monitoras, cujos dados representam a calibração dos segmentos dos filmes, na configuração definida, utilizada na dosimetria in vivo. 


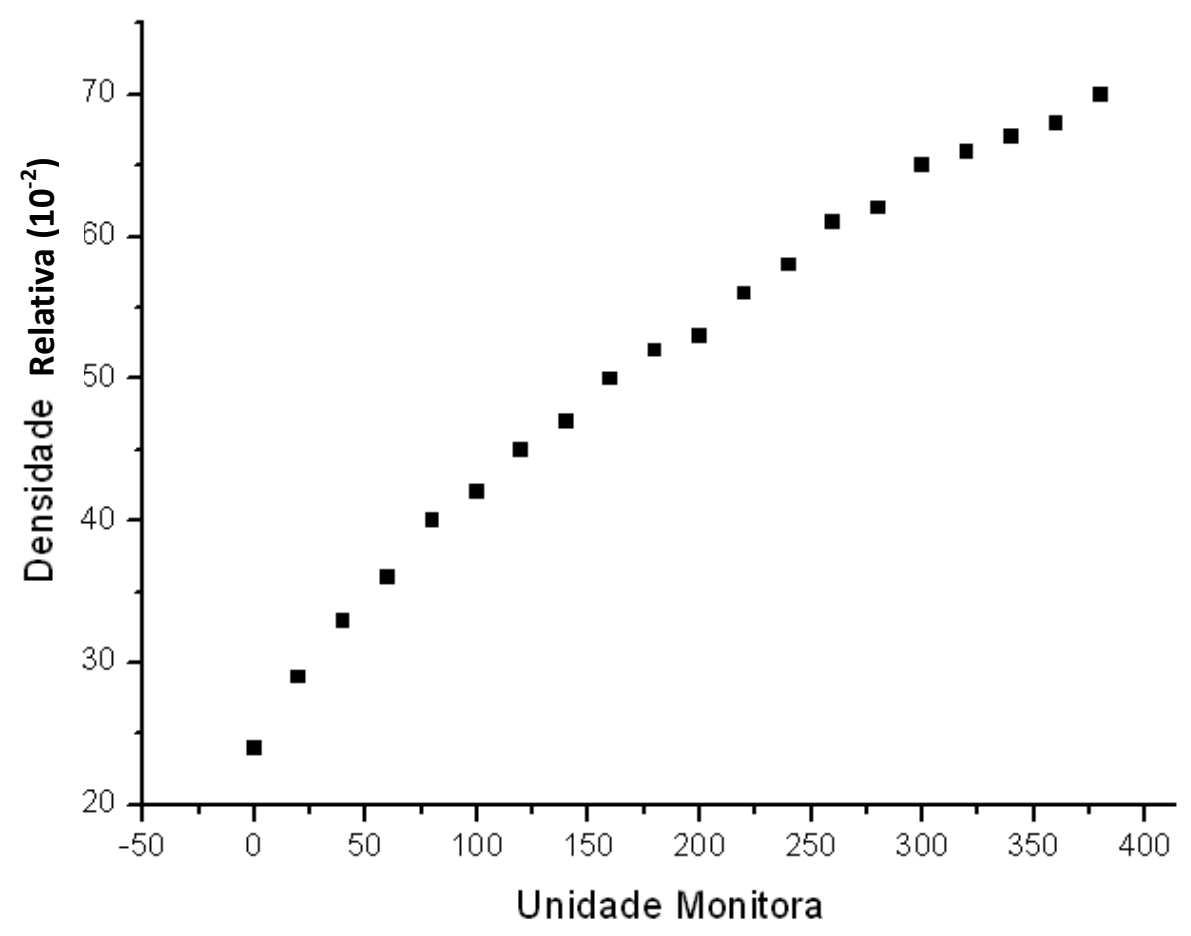

Figura 4.3 - Gráfico das densidades relativas em função das unidades monitoras dos segmentos de filmes utilizada na calibração da dosimetria in vivo.

\subsubsection{Dependência Dosimétrica da Dimensão do Campo}

A tabela 4.6 apresenta os dados da dependência dosimétrica da dimensão do campo (DDDC) na saída do cabeçote do mMLC. Os valores da DDDC foram obtidos pela divisão da densidade relativa do campo, em questão, pela densidade relativa do campo 50,3 mm.

Tabela 4.5 - Dados da dependência dosimétrica da dimensão do campo, a partir das densidades relativas (DR) em função do campo equivalente (Ceq).

\begin{tabular}{ccc}
\hline \hline Ceq $(\mathrm{mm})$ & DR & DDDC \\
\hline 10,2 & 0,400 & 0,952 \\
20,2 & 0,410 & 0,976 \\
30,6 & 0,415 & 0,988 \\
50,3 & 0,420 & 1,000 \\
70 & 0,430 & 1,024 \\
100 & 0,440 & 1,048 \\
\hline \hline
\end{tabular}

Desvio Padrão Máximo: 0,006 


\subsection{AVALIAÇÃO DA TÉCNICA DE DOSIMETRIA IN VIVO EM CINCO PLANOS}

Na avaliação da técnica, foram planejados cinco planos não co-planares com campos equivalentes médios variando de 22 a $53 \mathrm{~mm}$, em seguida, os planejamentos foram executados com os filmes acoplados na configuração desenvolvida para dosimetria in vivo. Posteriormente foram determinadas as densidades relativas destes filmes e comparadas com os valores pré-ditos calculados pelo sistema de cálculo previamente desenvolvido para este fim. Os valores das densidades relativas medidas e das calculadas estão apresentadas na tabela 4.7. MU representa as unidades monitoras, Ceq os campos equivalentes de cada campo, DR Med as densidades relativas medidas, DR Cal as densidades Óticas calculadas e Dif \% as diferenças percentuais entre as densidades relativas medidas com o densitômetro e as calculadas pela planilha computacional desenvolvida.

Tabela 4.6 - Resultado das diferenças percentuais entre as densidades relativas medidas e a calculadas pela planilha desenvolvida na dosimetria in vivo.

\begin{tabular}{cccccc}
\hline \hline Planos & UM & C. Eq $(\mathbf{m m})$ & DR Med & DR Cal & Dif \% \\
\hline P1 & 225 & 51 & 0,58 & 0,56 & 2,6 \\
P2 & 297 & 22 & 0,64 & 0,64 & $-1,7$ \\
P3 & 297 & 28 & 0,64 & 0,64 & $-0,9$ \\
P4 & 297 & 38 & 0,64 & 0,64 & $-0,9$ \\
P5 & 297 & 53 & 0,67 & 0,64 & 3,7 \\
\hline \hline
\end{tabular}

O valor médio da DR na verificação dosimétrica no momento da irradiação comparado com o calculado pela planilha foi de 1,5. A maior diferença foi de 3,7\% para o Campo Equivalente de $53 \mathrm{~mm}$ e a menor diferença $0,9 \%$ nos campos equivalentes de 28 e $38 \mathrm{~mm}$. Observa-se que a maior diferença percentual aparece nos campos maiores, com campos equivalentes de 51 e $53 \mathrm{~mm}$, isso pode acontecer, pois o cálculo da DR Cal não levou em consideração a diferença dosimétrica das dimensões do campo com relação ao MLC intrínseco do AL, sendo que essa diferença fica mais evidente em campos com dimensões maiores. 
Tunio e colaboradores em 2011(80) apresentou um estudo de dosimetria in vivo, com 1000 casos, realizado com o dosímetro constituído por diodo, em diversos sítios anatômicos, e as diferenças percentuais foram semelhantes ao encontrado neste estudo.

Na validação da técnica foi realizado um controle da qualidade convencional para os cinco campos planejados. O controle da qualidade convencional analisou a dose de referência no isocentro com câmara de ionização CC13 e com a função gama com filme radiocrômico. A tabela 4.6 apresenta as diferenças percentuais entre os valores medidos com câmara de ionização, localizados no eixo central do objeto simulador e os resultados apresentados pelo TPS para os cinco planos estudados.

Tabela 4.7 - Diferença percentual entre o valores medidos com câmara de ionização e o calculado pelo TPS.

\begin{tabular}{cccc}
\hline \hline Planos & TPS (cGy) & Cl (cGy) & Dif \% \\
\hline P1 & 155 & 151,9 & 2,0 \\
P2 & 186 & 180,6 & 3,0 \\
P3 & 193 & 187,3 & 3,0 \\
P4 & 202 & 197,1 & 2,5 \\
P5 & 212 & 207,9 & 2,0 \\
\hline \hline
\end{tabular}

Todos os valores da dosimetria absoluta, apresentados na tabela 4.8, são menores ou iguais a $3 \%$, portanto estando em conformidade com o TRS - 430.(49)

A tabela 4.9 apresenta o resultado da porcentagem dos pontos aprovados nos critérios $\Delta \%=2 \%$ e $\Delta \mathrm{d}=2 \mathrm{~mm}$ dos índices gama das matrizes de doses geradas, no plano coronal, a oito centímetros de profundidade no TPS e as matrizes geradas, pelos filmes radiocrômicos, na mesma posição, nos cinco planos analisados.

Tabela 4.8 - Porcentagem dos índices gama aprovados nos planos usados para validação da técnica de dosimetria in vivo. 


\begin{tabular}{cc} 
P1 & 99,8 \\
P2 & 98,9 \\
P3 & 99,7 \\
P4 & 99,4 \\
P5 & 99,6 \\
\hline Média & $\mathbf{9 9 , 4 8}$ \\
\hline \hline Desv. Padrão & 0,36
\end{tabular}

O ICRU e diversos trabalham admitem critérios para função gama maiores que os usados neste trabalho, utilizamos os critérios $\Delta \mathrm{D}=2 \%$ e $\Delta \mathrm{r}=2 \mathrm{~mm}$, pois estamos avaliando campos com dimensões reduzidas, porém mesmo sendo mais restritiva a porcentagem dos pontos aprovados estão acima dos valores usados na literatura, que admitem valores maiores que 95\%(74-77). No apêndice estão as imagens das funções gama coletadas do OmniPro.

Na tabela 4.8 pode-se observar que todas as dosimetrias de referência realizadas neste trabalho apresentaram critérios de limites de confiança abaixo de $2 \%$, que é o critério de limite de confiança mais restritivo do TRS - 430(49). Logo, encontra-se em concordância.

Tabela 4.9 - Desvio médio, desvio padrão e limite de confiança de todas as dosimetrias de referência realizadas neste trabalho.

\begin{tabular}{clccccc}
\hline \hline $\begin{array}{c}\text { Número } \\
\text { do teste }\end{array}$ & \multicolumn{1}{c}{$\begin{array}{c}\text { Geometria } \\
\text { do teste }\end{array}$} & $\begin{array}{c}\text { Número } \\
\text { de pontos }\end{array}$ & $\begin{array}{c}\text { Desvio } \\
\text { médio }\end{array}$ & $\begin{array}{c}\text { Desvio } \\
\text { padrão }\end{array}$ & $\begin{array}{c}\text { Limite de } \\
\text { confiaça }\end{array}$ & $\begin{array}{c}\text { critério do } \\
\text { TRS - 430 }\end{array}$ \\
\hline & & & & & & \\
1 & Campos quadrados no eixo central & - & - & - & - & $\pm 2 \%$ \\
2 & Campos ciculares com mMLC & 5 & 0,28 & 0,37 & 0,83 & $\pm 2 \%$ \\
3 & Campos com objetos simuladores herogêneos & 6 & 0,39 & 0,59 & 1,28 & $\pm 3 \%$ \\
4 & Combinação de campos oblicuos na validação & 5 & 0,41 & 0,51 & 1,17 & $\pm 4 \%$ \\
\hline \hline
\end{tabular}


Capítulo 5 - Conclusões 


\section{CONCLUSÕES}

O sistema de planejamento é uma ferramenta importante em radioterapia, pois possibilita os cálculos das interações do feixe radioativo no organismo humano. Por esta razão a realização precisa do comissionamento garante um adequado controle da qualidade dos tratamentos em radioterapia estereotáxica.

- Os valores apresentados na dosimetria de referência com os campos diretos com mMLC e com os objetos simuladores heterogêneos, mostraram diferenças percentuais inferiores a 3\%. Assim, estando em concordância com os limites estabelecidos pelo TRS-430 e, portanto, adequados para uso clínico.

O grande número de campos utilizados em radioterapia estereotáxica e suas pequenas dimensões dificultam as aplicações das técnicas convencionais de dosimetria in vivo, que utilizam os dosímetros colocados em contato com o paciente. Assim, o método de acoplar o dosímetro no cabeçote do aparelho mostrou ser uma alternativa viável para avaliações dosimétricas.

- Os dados coletados neste estudo apresentaram uma concordância satisfatória entre os valores calculados pelo programa computacional desenvolvido neste trabalho e os medidos com o densitômetro.

- O controle da qualidade convencional validou o processo da dosimetria in vivo confirmando assim, os dados adquiridos na dosimetria.

Apesar da técnica de dosimetria in vivo desenvolvida neste trabalho só garantir a liberação da dose do AL no eixo central, o objetivo do trabalho foi alcançado, pois os aparatos 
estereotáxicos garantiram o posicionamento adequado do paciente além de que, o controle da qualidade convencional mostrou que todo processo dosimétrico envolvido na radioterapia estereotáxica apresenta-se satisfatório.

Desta forma, conclui-se que foi elaborada parte de um programa de controle da qualidade dosimétrico para a técnica de radioterapia estereotáxica no serviço de radioterapia do Hospital das Clinicas da Faculdade de Medicina de Ribeirão Preto - USP, com a validação de alguns parâmetros do comissionamento do sistema de planejamento e com o desenvolvimento da técnica de dosimetria in vivo com filme radiocrômico.

Nossa perspectiva futura é adaptar este método de dosimetria in vivo, com filme radiocrômico acoplado no cabeçote do aparelho, para outros tipos de tratamentos radioterápicos, como: radioterapia conformacional, IMRT, radiocirurgia e irradiação de corpo inteiro, além de aprimorar a referida técnica para que seja capaz de avaliar a fluência em todos os tipos de tratamentos teleterápicos. 
Capítulo 6. Referências Bibliográficas 


\section{REFERÊNCIAS BIBLIOGRÁFICAS}

1. Filippini G. Epidemiology of primary central nervous system tumors. Handb Clin Neurol. 2012;104:3-22.

2. Lo SS, Sahgal A, Ma L, Chang EL. Advances in radiation therapy of brain metastasis. Prog Neurol Surg. 2012;25:96-109.

3. Zhang X, Zhang W, Cao WD, Cheng G, Liu B, Cheng J. A Review of Current Management of Brain Metastases. Ann Surg Oncol. 2011 Aug 23.

4. Hacker FL, Kooy HM, Bellerive MR, Killoran JH, Leber ZH, Shrieve DC, et al. Beam shaping for conformal fractionated stereotactic radiotherapy: a modeling study. Int J Radiat Oncol Biol Phys. 1997 Jul 15;38(5):1113-21.

5. Wang YY, Yang GK, Li SY, Baol XF, Wu CY. Prognostic factors for deep situated malignant gliomas treated with linac radiosurgery. Chin Med Sci J. 2004 Jun;19(2):105-10.

6. Yang DY, Sheehan J, Liu YS, ChangLai SP, Pan HC, Chen CJ, et al. Analysis of factors associated with volumetric data errors in gamma knife radiosurgery. Stereotact Funct Neurosurg. 2009;87(1):1-7.

7. McKerracher C, Thwaites DI. Verification of the dose to the isocentre in stereotactic plans. Radiother Oncol. 2002 Jul;64(1):97-107.

8. Grebe G, Pfaender M, Roll M, Luedemann L, Wurm RE. Dynamic arc radiosurgery and radiotherapy: commissioning and verification of dose distributions. Int J Radiat Oncol Biol Phys. 2001 Apr 1;49(5):1451-60.

9. AAPM Radiation Therapy Committee. Task Group 42. Stereotactic Radiosurgery. AAPM. 1995:92.

10. Yang JN, Pino R. Analytical calculation of central-axis dosimetric data for a dedicated 6-MV radiosurgery linear accelerator. Med Phys. 2008 Oct;35(10):4333-41.

11. Urie MM, Lo YC, Litofsky S, FitzGerald TJ. Miniature multileaf collimator as an alternative to traditional circular collimators for stereotactic radiosurgery and stereotactic radiotherapy. Stereotact Funct Neurosurg. 2001;76(1):47-62. 
12. Cosgrove VP, Jahn U, Pfaender M, Bauer S, Budach V, Wurm RE. Commissioning of a micro multi-leaf collimator and planning system for stereotactic radiosurgery. Radiother Oncol. 1999 Mar;50(3):325-36.

13. Abrego FC, Calcina CS, de Almeida A, de Almeida CE, Baffa O. Relative output factor and beam profile measurements of small radiation fields with an L-alanine/K-band EPR minidosimeter. Med Phys. 2007 May;34(5):1573-82.

14. Butson MJ, Yu PK, Cheung T. Rounded end multi-leaf penumbral measurements with radiochromic film. Phys Med Biol. 2003 Sep 7;48(17):N247-52.

15. Chen F, Graeff CF, Baffa O. K-band EPR dosimetry: small-field beam profile determination with miniature alanine dosimeter. Appl Radiat Isot. 2005 Feb;62(2):267-71.

16. Dempsey JF, Low DA, Mutic S, Markman J, Kirov AS, Nussbaum GH, et al. Validation of a precision radiochromic film dosimetry system for quantitative twodimensional imaging of acute exposure dose distributions. Med Phys. 2000 Oct;27(10):246275.

17. Meeks SL, Bova FJ, Maryanski MJ, Kendrick LA, Ranade MK, Buatti JM, et al. Image registration of BANG gel dose maps for quantitative dosimetry verification. Int $\mathrm{J}$ Radiat Oncol Biol Phys. 1999 Mar 15;43(5):1135-41.

18. Pappas E, Maris TG, Zacharopoulou F, Papadakis A, Manolopoulos S, Green S, et al. Small SRS photon field profile dosimetry performed using a PinPoint air ion chamber, a diamond detector, a novel silicon-diode array (DOSI), and polymer gel dosimetry. Analysis and intercomparison. Med Phys. 2008 Oct;35(10):4640-8.

19. Butson MJ, Cheung T, Yu PK. Radiochromic film for verification of superficial x-ray backscatter factors. Australas Phys Eng Sci Med. 2007 Dec;30(4):269-73.

20. Butson MJ, Cheung T, Yu PK. Spatial resolution of a stacked radiochromic film dosimeter. Radiother Oncol. 2001 Nov;61(2):211-3.

21. Bushong SC. Radiologic science for technologist : physics, biology, and protection. 9th ed. St. Louis, Mo.: Mosby/Elsevier; 2008.

22. Butson MJ, Cheung T, Yu PK. Measurement of energy dependence for XRCT radiochromic film. Med Phys. 2006 Aug;33(8):2923-5.

23. Butson MJ, Cheung T, Yu PK. Measuring energy response for RTQA radiochromic film to improve quality assurance procedures. Australas Phys Eng Sci Med. 2008 Sep;31(3):203-6.

24. Butson MJ, Yu PK, Cheung T, Metcalfe P. High sensitivity radiochromic film dose comparisons. Phys Med Biol. 2002 Nov 21;47(22):N291-5. 
25. Yu PK, Butson M, Cheung T. Does mechanical pressure on radiochromic film affect optical absorption and dosimetry? Australas Phys Eng Sci Med. 2006 Sep;29(3):285-7.

26. Tecdoc 1151. Aspectos Físicos da Garantia da Qualidade em Radioterapia - Protocolo de Controle de Qualidade. Rio de Janeiro: INCA; 2000.

27. Deng J, Ma CM, Hai J, Nath R. Commissioning $6 \mathrm{MV}$ photon beams of a stereotactic radiosurgery system for Monte Carlo treatment planning. Med Phys. 2003 Dec;30(12):312434.

28. Yang JN, Ding X, Du W, Pino R. Model-based calculations of off-axis ratio of conic beams for a dedicated 6 MV radiosurgery unit. Med Phys. 2010 Oct;37(10):5442-7.

29. Narayan S, Lehmann J, Coleman MA, Vaughan A, Yang CC, Enepekides D, et al. Prospective evaluation to establish a dose response for clinical oral mucositis in patients undergoing head-and-neck conformal radiotherapy. Int J Radiat Oncol Biol Phys. 2008 Nov $1 ; 72(3): 756-62$.

30. Piermattei A, Fidanzio A, Azario L, Greco F, Mameli A, Cilla S, et al. In patient dose reconstruction using a cine acquisition for dynamic arc radiation therapy. Med Biol Eng Comput. 2009 Apr;47(4):425-33.

31. Belletti S, Dutreix A, Garavaglia G, Gfirtner H, Haywood J, Jessen KA, et al. Quality assurance in radiotherapy: the importance of medical physics staffing levels. Recommendations from an ESTRO/EFOMP joint task group. Radiother Oncol. 1996 Oct;41(1):89-94.

32. Butson MJ, Cheung T, Yu PK, Price S, Bailey M. Measurement of radiotherapy superficial X-ray dose under eye shields with radiochromic film. Phys Med. 2008 Mar;24(1):29-33.

33. Butson MJ, Mathur JN, Metcalfe PE. Radiochromic film as a radiotherapy surfacedose detector. Phys Med Biol. 1996 Jun;41(6):1073-8.

34. Piermattei A, Stimato G, Gaudino D, Ramella S, D'Angelillo RM, Cellini F, et al. Dynamic conformal arc therapy: transmitted signal in vivo dosimetry. Med Phys. 2008 May;35(5):1830-9.

35. Tung CJ, Wang HC, Lo SH, Wu JM, Wang CJ. In vivo dosimetry for external photon treatments of head and neck cancers by diodes and TLDS. Radiat Prot Dosimetry. 2004;111(1):45-50.

36. Bitelli T. Física e Dosimetria das radiações. Segunda Edição ed: Atheneu; 2006.

37. Hall EJ, Giaccia AJ. Radiobiology for the radiologist. 6th ed. Philadelphia: Lippincott Williams \& Wilkins; 2006. 
38. Halliday D, Resnick R, Walker J. Fundamentals of physics. 6th ed. New York: John Wiley \& Sons; 2001.

39. Johns HE, Cunningham JR. The physics of radiology. 4th ed. Springfield, Ill., U.S.A.: Charles C. Thomas; 1983.

40. Tipler PA, Llewellyn RA. Modern physics. 5th ed. New York, NY: W.H. Freeman; 2008.

41. Okuno E. Física para Ciências Biológicas e Biomédicas. São Paulo: Habra.

42. Khan FM. Khan's lectures : handbook of the physics of radiation therapy. Philadelphia: Wolters Kluwer/Lippincott Williams \& Wilkins Health; 2012.

43. Salvajoli JV. Radioterapia em Oncologia1999.

44. Khan FM. The physics of radiation therapy. 4th ed. Philadelphia: Lippincott Williams \& Wilkins; 2010.

45. Chavaudra J, Bridier A. [Definition of volumes in external radiotherapy: ICRU reports 50 and 62]. Cancer Radiother. 2001 Oct;5(5):472-8.

46. Stroom JC, Heijmen BJ. Geometrical uncertainties, radiotherapy planning margins, and the ICRU-62 report. Radiother Oncol. 2002 Jul;64(1):75-83.

47. AAPM Radiation Therapy Committee. Task Group 24. Physical aspects of quality assurance in radiation therapy. New York, NY: Published for the American Association of Physicists in Medicine by the American Institute of Physics; 1984.

48. Schlegel W, Bortfeld T, Grosu A. New technologies in radiation oncology. Berlin ; London: Springer; 2005.

49. International Atomic Energy Agency TRS-430. Commissioning and quality assurance of computerized planning systems for radiation treatment of cancer. IAEA. 2004;430:302.

50. Wang L, Li J, Paskalev K, Hoban P, Luo W, Chen L, et al. Commissioning and quality assurance of a commercial stereotactic treatment-planning system for extracranial IMRT. J Appl Clin Med Phys. 2006 Winter;7(1):21-34.

51. Soanes T, Hampshire A, Vaughan P, Brownett C, Rowe J, Radatz M, et al. The commissioning and quality assurance of the Automatic Positioning System on the Leksell gamma knife. J Neurosurg. 2002 Dec;97(5 Suppl):574-8.

52. AAPM Radiation Therapy Committee. Task Group 65. Tissue Inhomogeneity Corrections For Megavoltage P. 2004.

53. Low DA, Harms WB, Mutic S, Purdy JA. A technique for the quantitative evaluation of dose distributions. Med Phys. 1998 May;25(5):656-61. 
54. Venselaar J, Welleweerd H. Application of a test package in an intercomparison of the photon dose calculation performance of treatment planning systems used in a clinical setting. Radiother Oncol. 2001 Aug;60(2):203-13.

55. Venselaar J, Welleweerd H, Mijnheer B. Tolerances for the accuracy of photon beam dose calculations of treatment planning systems. Radiother Oncol. 2001 Aug;60(2):191-201.

56. Fraass B, Doppke K, Hunt M, Kutcher G, Starkschall G, Stern R, et al. American Association of Physicists in Medicine Radiation Therapy Committee Task Group 53: quality assurance for clinical radiotherapy treatment planning. Med Phys. 1998 Oct;25(10):1773-829.

57. Attix FH. Introduction to radiological physics and radiation dosimetry. New York: Wiley; 1986.

58. International Atomic Energy Agency. Absorbed dose determination in external beam radiotherapy : an international code of practice for dsimetry based on standards of absorbed dose to water. Vienna: International Atomic Energy Agency; 2001.

59. Malicki J, Litoborski M, Bogusz-Czerniewicz M, Swiezewski A. Cost-effectiveness of the modifications in the quality assurance system in radiotherapy in the example of in-vivo dosimetry. Phys Med. 2009 Dec;25(4):201-6.

60. Ismail A, Giraud JY, Lu GN, Sihanath R, Pittet P, Galvan JM, et al. Radiotherapy quality assurance by individualized in vivo dosimetry: state of the art. Cancer Radiother. 2009 Jun;13(3):182-9.

61. Leunens G, Van Dam J, Dutreix A, van der Schueren E. Quality assurance in radiotherapy by in vivo dosimetry. 2 . Determination of the target absorbed dose. Radiother Oncol. 1990 Sep;19(1):73-87.

62. Leunens G, Van Dam J, Dutreix A, van der Schueren E. Quality assurance in radiotherapy by in vivo dosimetry. 1. Entrance dose measurements, a reliable procedure. Radiother Oncol. 1990 Feb;17(2):141-51.

63. Butson MJ, Cheung T, Yu PK. Radiochromic film dosimetry in water phantoms. Phys Med Biol. 2001 Jan;46(1):N27-31.

64. Alnawaf H, Butson MJ, Cheung T, Yu PK. Scanning orientation and polarization effects for XRQA radiochromic film. Phys Med. 2010 Oct;26(4):216-9.

65. Butson E, Alnawaf H, Yu PK, Butson M. Scanner uniformity improvements for radiochromic film analysis with matt reflectance backing. Australas Phys Eng Sci Med. 2011 Jul 7. 
66. Carolan MG, Butson MJ, Herrmann K, Mathur JN, Metcalfe PE. Conversion of an infrared densitometer for radiochromic film analysis. Australas Phys Eng Sci Med. 1997 Sep;20(3):183-5.

67. Suchowerska N, Hoban P, Butson M, Davison A, Metcalfe P. Directional dependence in film dosimetry: radiographic and radiochromic film. Phys Med Biol. 2001 May;46(5):1391-7.

68. Zeidan OA, Stephenson SA, Meeks SL, Wagner TH, Willoughby TR, Kupelian PA, et al. Characterization and use of EBT radiochromic film for IMRT dose verification. Med Phys. 2006 Nov;33(11):4064-72.

69. Wilcox EE, Daskalov GM. Evaluation of GAFCHROMIC EBT film for Cyberknife dosimetry. Med Phys. 2007 Jun;34(6):1967-74.

70. Wilcox EE, Daskalov GM. Accuracy of dose measurements and calculations within and beyond heterogeneous tissues for $6 \mathrm{MV}$ photon fields smaller than $4 \mathrm{~cm}$ produced by Cyberknife. Med Phys. 2008 Jun;35(6):2259-66.

71. Kishor Mehta AP. Characterization and dosimetry of a practical X-ray alternative to self-shielded gamma irradiators. Radiation Physics and Chemistry. 2010;80(1):107-13

72. B. MC McCurdy LM, E. Backman, S. Venkataraman, E. Fleming, G. Asuni, M. Jensen, F. Ur-Rehmann,, Pistorius S. Commissioning and validation of a novel measurementbased IMRT QA method, incorporating dose recalculation on patient CT data. MedPhys. $2008 ; 35(6)$

73. GAFCHROMIC EBT2 Dosimetry Film; www.gafchromic.com.br. 2009.

74. Fogliata A, Nicolini G, Clivio A, Vanetti E, Cozzi L. Accuracy of Acuros XB and AAA dose calculation for small fields with reference to $\operatorname{RapidArc}((\mathrm{R}))$ stereotactic treatments. Med Phys. 2011 Nov;38(11):6228.

75. Kozelka J, Robinson J, Nelms B, Zhang G, Savitskij D, Feygelman V. Optimizing the accuracy of a helical diode array dosimeter: a comprehensive calibration methodology coupled with a novel virtual inclinometer. Med Phys. 2011 Sep;38(9):5021-32.

76. Sakhalkar HS, Adamovics J, Ibbott G, Oldham M. An Investigation into the Robustness of Optical-CT Dosimetry of a Radiochromic Dosimeter Compatible with the RPC Head-and-Neck Phantom. J Phys. 2009 Jan 1;164(1):12059.

77. ICRU. Prescribing, Recording and Reporting Intesity-modulated photon-bean Therapy (IMRT), Report 83. International Commission on Radaition Units and Measurements. 2010.

78. Fairbanks LR BG, Silva WT, Reis EGF, Borges LF, Bertucci EC, Maciel MF e Amaral LL. Validação dos algoritmos de cálculo de dose do sistema de planejamento XiOß 
considerando as correções para heterogeneidade dos tecidos. Revista Brasileira de Física Médica. 2011;4(3):79-82.

79. T. Kairn SC, J. Kenny, J. V. Trapp. Investigation of stereotactic radiotherapy dose using dosimetry Film and Monte Carlo simulations. Radiation Measurements. 2010.

80. Mutahir Tunio MR, Shoukat Ali, Zaeem Ahmed, Asad Zameer, Altaf Hashmi and, Maqboo SA. In vivo dosimetry with diodes in a radiotherapy department in pakistan. Radiation Protection Dosimetry. 2011;147(4):608-13. 
Capitulo 7. Apêndices 


\section{Apêndices}

\subsection{Dados dos planos da dosimetria IN VIVO}

\subsubsection{Plano1}

\section{PLANO 1}

\begin{tabular}{|c|c|c|c|c|c|c|c|c|c|c|c|}
\hline Campos & Prof. & $\mathbf{C}_{\text {eq }}$ & Dose (cGy) & Mesa & Gantry & Colimador & X1 & X2 & Y1 & Y2 & UM $_{\text {iPlan }}$ \\
\hline 1 & 96 & 51 & 10,3 & 270 & 25 & 0 & -38 & 37 & -28 & 28 & 14 \\
\hline 2 & 96 & 50 & 10,2 & 270 & 58 & 0 & -39 & 36 & -28 & 28 & 14 \\
\hline 3 & 77 & 48 & 10,9 & 270 & 90 & 0 & -32 & 37 & -28 & 28 & 14 \\
\hline 4 & 91 & 49 & 11,1 & 270 & 120 & 0 & -37 & 35 & -28 & 28 & 15 \\
\hline 5 & 113 & 49 & 10,9 & 270 & 141 & 0 & -36 & 34 & -28 & 28 & 16 \\
\hline 6 & 94 & 49 & 11,8 & 45 & 337 & 0 & -32 & 36 & -36 & 31 & 16 \\
\hline 7 & 143 & 51 & 9,8 & 45 & 306 & 0 & -36 & 37 & -36 & 31 & 16 \\
\hline 8 & 116 & 52 & 10,9 & 45 & 270 & 0 & -37 & 32 & -36 & 31 & 16 \\
\hline 9 & 128 & 53 & 11,1 & 45 & 244 & 0 & -38 & 36 & -36 & 31 & 17 \\
\hline 10 & 119 & 53 & 12,1 & 45 & 222 & 0 & -39 & 35 & -36 & 31 & 18 \\
\hline 11 & 100 & 54 & 10,2 & 315 & 30 & 0 & -35 & 35 & -36 & 33 & 14 \\
\hline 12 & 138 & 55 & 8 & 315 & 56 & 0 & -35 & 36 & -36 & 33 & 13 \\
\hline 13 & 115 & 54 & 8,9 & 315 & 90 & 0 & -32 & 37 & -33 & 33 & 13 \\
\hline 14 & 132 & 51 & 8,9 & 315 & 119 & 0 & -34 & 35 & -33 & 33 & 14 \\
\hline 15 & 112 & 49 & 10,3 & 315 & 141 & 0 & -32 & 37 & -33 & 33 & 15 \\
\hline
\end{tabular}




\subsubsection{Plano2}

PLANO 2

\begin{tabular}{|c|c|c|c|c|c|c|c|c|c|c|c|}
\hline Campos & Prof. & $\mathrm{C}_{\text {eq }}$ & Dose (cGy) & Mesa & Gantry & Colimador & X1 & X2 & Y1 & Y2 & UM $_{\text {iPlan }}$ \\
\hline 1 & 97 & 24 & 8 & 270 & 27 & 0 & -16 & 15 & -18 & 21 & 12 \\
\hline 2 & 114 & 24 & 7 & 270 & 46 & 0 & -17 & 16 & -18 & 21 & 12 \\
\hline 3 & 87 & 24 & 8 & 270 & 67 & 0 & -18 & 16 & -18 & 21 & 12 \\
\hline 4 & 77 & 23 & 8 & 270 & 89 & 0 & -16 & 16 & -18 & 21 & 12 \\
\hline 5 & 102 & 23 & 9 & 270 & 149 & 0 & -15 & 15 & -18 & 21 & 14 \\
\hline 6 & 97 & 22 & 8 & 30 & 333 & 0 & -19 & 18 & -16 & -16 & 12 \\
\hline 7 & 128 & 22 & 7 & 30 & 313 & 0 & -18 & 18 & -16 & 16 & 12 \\
\hline 8 & 102 & 21 & 7 & 30 & 278 & 0 & -16 & 16 & -16 & 16 & 11 \\
\hline 9 & 102 & 21 & 8 & 30 & 264 & 0 & -17 & 16 & -16 & 16 & 12 \\
\hline 10 & 116 & 21 & 7 & 30 & 245 & 0 & -17 & 16 & -16 & 16 & 12 \\
\hline 11 & 100 & 23 & 8 & 60 & 331 & 0 & -16 & 18 & -18 & 18 & 12 \\
\hline 12 & 125 & 23 & 7 & 60 & 314 & 0 & 17 & 18 & -18 & 18 & 12 \\
\hline 13 & 107 & 23 & 8 & 60 & 298 & 0 & -17 & 18 & -18 & 18 & 12 \\
\hline 14 & 95 & 23 & 8 & 60 & 280 & 0 & -16 & 17 & -18 & 18 & 12 \\
\hline 15 & 95 & 22 & 8 & 60 & 260 & 0 & -17 & 16 & -18 & 18 & 12 \\
\hline 16 & 95 & 22 & 7 & 330 & 24 & 0 & -18 & 18 & -16 & 16 & 11 \\
\hline 17 & 109 & 22 & 7 & 330 & 37 & 0 & -18 & 17 & -16 & 16 & 11 \\
\hline 18 & 109 & 21 & 7 & 330 & 78 & 0 & -17 & 16 & -16 & 16 & 11 \\
\hline 19 & 107 & 21 & 7 & 330 & 101 & 0 & -16 & 16 & -16 & 16 & 12 \\
\hline 20 & 123 & 21 & 7 & 330 & 120 & 0 & -17 & 16 & -16 & 16 & 12 \\
\hline 21 & 111 & 23 & 7 & 300 & 38 & 0 & -18 & 17 & -18 & 18 & 12 \\
\hline 22 & 118 & 23 & 7 & 300 & 53 & 0 & -18 & 17 & -18 & 18 & 12 \\
\hline 23 & 100 & 23 & 7 & 300 & 69 & 0 & -18 & 16 & -18 & 18 & 11 \\
\hline 24 & 94 & 23 & 8 & 300 & 87 & 0 & -17 & 16 & -18 & 18 & 12 \\
\hline 25 & 95 & 22 & 8 & 300 & 101 & 0 & -16 & 17 & -18 & 18 & 12 \\
\hline
\end{tabular}




\subsubsection{Plano3}

\section{PLANO 3}

\begin{tabular}{|c|c|c|c|c|c|c|c|c|c|c|c|}
\hline Campos & Prof. & C $_{\text {eq }}$ & Dose (cGy) & Mesa & Gantry & Colimador & X1 & X2 & Y1 & Y2 & UM $_{\text {iplan }}$ \\
\hline 1 & 97 & 29 & 8 & 270 & 27 & 0 & -19 & 18 & -21 & 23 & 12 \\
\hline 2 & 114 & 29 & 8 & 270 & 46 & 0 & -20 & 19 & -21 & 23 & 12 \\
\hline 3 & 87 & 29 & 8 & 270 & 67 & 0 & -21 & 19 & -21 & 23 & 12 \\
\hline 4 & 77 & 28 & 9 & 270 & 89 & 0 & -19 & 19 & -21 & 23 & 12 \\
\hline 5 & 102 & 28 & 9 & 270 & 149 & 0 & -18 & 18 & -21 & 23 & 14 \\
\hline 6 & 97 & 28 & 8 & 30 & 333 & 0 & -22 & 21 & -18 & 18 & 12 \\
\hline 7 & 128 & 28 & 7 & 30 & 313 & 0 & -21 & 21 & -18 & 18 & 12 \\
\hline 8 & 102 & 26 & 7 & 30 & 278 & 0 & -19 & 19 & -18 & 18 & 11 \\
\hline 9 & 102 & 27 & 8 & 30 & 264 & 0 & -20 & 19 & -18 & 18 & 12 \\
\hline 10 & 116 & 27 & 7 & 30 & 245 & 0 & -20 & 19 & -18 & 18 & 12 \\
\hline 11 & 100 & 29 & 8 & 60 & 331 & 0 & -19 & 21 & -21 & 21 & 12 \\
\hline 12 & 125 & 29 & 7 & 60 & 314 & 0 & -20 & 21 & -21 & 21 & 12 \\
\hline 13 & 107 & 29 & 8 & 60 & 298 & 0 & -20 & 21 & -21 & 21 & 12 \\
\hline 14 & 95 & 28 & 8 & 60 & 280 & 0 & -19 & 20 & -21 & 21 & 12 \\
\hline 15 & 95 & 28 & 8 & 60 & 260 & 0 & -20 & 19 & -21 & 21 & 12 \\
\hline 16 & 95 & 28 & 7 & 330 & 24 & 0 & -21 & 21 & -18 & 18 & 11 \\
\hline 17 & 109 & 27 & 7 & 330 & 37 & 0 & -21 & 20 & -18 & 18 & 11 \\
\hline 18 & 109 & 27 & 7 & 330 & 78 & 0 & -20 & 19 & -18 & 18 & 11 \\
\hline 19 & 107 & 26 & 8 & 330 & 101 & 0 & -19 & 19 & -18 & 18 & 12 \\
\hline 20 & 123 & 27 & 7 & 330 & 120 & 0 & -20 & 19 & -18 & 18 & 12 \\
\hline 21 & 111 & 29 & 8 & 300 & 38 & 0 & -21 & 20 & -21 & 23 & 12 \\
\hline 22 & 118 & 29 & 7 & 300 & 53 & 0 & -21 & 20 & -21 & 23 & 12 \\
\hline 23 & 100 & 29 & 7 & 300 & 69 & 0 & -21 & 19 & -21 & 23 & 11 \\
\hline 24 & 94 & 29 & 8 & 300 & 87 & 0 & -20 & 19 & -21 & -23 & 12 \\
\hline 25 & 95 & 28 & 8 & 300 & 101 & 0 & -19 & 20 & -21 & 23 & 12 \\
\hline & & & & & & & & & \\
\hline
\end{tabular}




\subsubsection{Plano4}

\section{PLANO 4}

\begin{tabular}{|c|c|c|c|c|c|c|c|c|c|c|c|}
\hline Campos & Prof. & C $_{\text {eq }}$ & Dose (cGy) & Mesa & Gantry & Colimador & X1 & X2 & Y1 & Y2 & UM $_{\text {iPlan }}$ \\
\hline 1 & 97 & 40 & 8 & 270 & 27 & 0 & -25 & 24 & -28 & 28 & 12 \\
\hline 2 & 114 & 40 & 8 & 270 & 46 & 0 & -26 & 25 & -28 & 28 & 12 \\
\hline 3 & 87 & 40 & 9 & 270 & 67 & 0 & -27 & 25 & -28 & 28 & 12 \\
\hline 4 & 77 & 39 & 9 & 270 & 89 & 0 & -25 & 25 & -28 & 28 & 12 \\
\hline 5 & 102 & 39 & 10 & 270 & 149 & 0 & -24 & 24 & -28 & 28 & 14 \\
\hline 6 & 97 & 39 & 8 & 30 & 333 & 0 & -28 & 27 & -26 & 26 & 12 \\
\hline 7 & 128 & 38 & 7 & 30 & 313 & 0 & -27 & 27 & -26 & 26 & 12 \\
\hline 8 & 102 & 37 & 8 & 30 & 278 & 0 & -25 & 25 & -26 & 26 & 11 \\
\hline 9 & 102 & 37 & 8 & 30 & 264 & 0 & -26 & 25 & -26 & 26 & 12 \\
\hline 10 & 116 & 37 & 8 & 30 & 245 & 0 & -26 & 25 & -26 & 26 & 12 \\
\hline 11 & 100 & 39 & 8 & 60 & 331 & 0 & -25 & 27 & -26 & 28 & 12 \\
\hline 12 & 125 & 40 & 8 & 60 & 314 & 0 & -26 & 27 & -26 & 28 & 12 \\
\hline 13 & 107 & 39 & 8 & 60 & 298 & 0 & -26 & 27 & -26 & 28 & 12 \\
\hline 14 & 95 & 39 & 9 & 60 & 280 & 0 & -25 & 26 & -26 & 28 & 12 \\
\hline 15 & 95 & 38 & 8 & 60 & 260 & 0 & -26 & 25 & -26 & 28 & 12 \\
\hline 16 & 95 & 39 & 8 & 330 & 24 & 0 & -27 & 27 & -26 & 26 & 11 \\
\hline 17 & 109 & 39 & 7 & 330 & 37 & 0 & -26 & 26 & -26 & 26 & 11 \\
\hline 18 & 109 & 38 & 7 & 330 & 78 & 0 & -26 & 25 & -26 & 26 & 11 \\
\hline 19 & 107 & 38 & 8 & 330 & 101 & 0 & -25 & 25 & -26 & 26 & 12 \\
\hline 20 & 123 & 38 & 8 & 330 & 120 & 0 & -26 & 25 & -26 & 26 & 12 \\
\hline 21 & 111 & 40 & 8 & 300 & 38 & 0 & -27 & 26 & -28 & 28 & 12 \\
\hline 22 & 118 & 40 & 8 & 300 & 53 & 0 & -27 & 26 & -28 & 28 & 12 \\
\hline 23 & 100 & 40 & 8 & 300 & 69 & 0 & -27 & 25 & -28 & 28 & 11 \\
\hline 24 & 94 & 39 & 8 & 300 & 87 & 0 & -26 & 25 & -28 & 28 & 12 \\
\hline 25 & 95 & 39 & 8 & 300 & 101 & 0 & -25 & 26 & -28 & 28 & 12 \\
\hline & & & & & & & 0 & \\
\hline
\end{tabular}




\subsubsection{Plano5}

\section{PLANO 5}

\begin{tabular}{|c|c|c|c|c|c|c|c|c|c|c|c|}
\hline Campos & Prof. & $\mathbf{C}_{\text {eq }}$ & Dose (cGy) & Mesa & Gantry & Colimador & X1 & X2 & Y1 & Y2 & UM $_{\text {iPlan }}$ \\
\hline 1 & 97 & 54 & 9 & 270 & 27 & 0 & -33 & 32 & -36 & 36 & 12 \\
\hline 2 & 114 & 54 & 8 & 270 & 46 & 0 & -34 & 33 & -36 & 36 & 12 \\
\hline 3 & 87 & 54 & 9 & 270 & 67 & 0 & -35 & 33 & -36 & 36 & 12 \\
\hline 4 & 77 & 53 & 9 & 270 & 89 & 0 & -33 & 33 & -36 & 36 & 12 \\
\hline 5 & 102 & 53 & 10 & 270 & 149 & 0 & -32 & 32 & -36 & 36 & 14 \\
\hline 6 & 97 & 53 & 9 & 30 & 333 & 0 & -36 & 35 & -33 & 33 & 12 \\
\hline 7 & 128 & 53 & 8 & 30 & 313 & 0 & -35 & 35 & -33 & 33 & 12 \\
\hline 8 & 102 & 52 & 8 & 30 & 278 & 0 & -33 & 33 & -33 & 33 & 11 \\
\hline 9 & 102 & 52 & 9 & 30 & 264 & 0 & -34 & 33 & -33 & 33 & 12 \\
\hline 10 & 116 & 51 & 8 & 30 & 245 & 0 & -34 & 33 & -33 & 33 & 12 \\
\hline 11 & 100 & 54 & 9 & 60 & 331 & 0 & -33 & 35 & -36 & 36 & 12 \\
\hline 12 & 125 & 54 & 8 & 60 & 314 & 0 & -34 & 35 & -36 & 36 & 12 \\
\hline 13 & 107 & 54 & 9 & 60 & 298 & 0 & -34 & 35 & -36 & 36 & 12 \\
\hline 14 & 95 & 53 & 9 & 60 & 280 & 0 & -33 & 34 & -36 & 36 & 12 \\
\hline 15 & 95 & 53 & 9 & 60 & 260 & 0 & -34 & 33 & -36 & 36 & 12 \\
\hline 16 & 95 & 53 & 8 & 330 & 24 & 0 & -35 & 35 & -33 & 33 & 11 \\
\hline 17 & 109 & 53 & 8 & 330 & 37 & 0 & -35 & 34 & -33 & 33 & 11 \\
\hline 18 & 109 & 52 & 8 & 330 & 78 & 0 & -34 & 33 & -33 & 33 & 11 \\
\hline 19 & 107 & 52 & 8 & 330 & 101 & 0 & -33 & 33 & -33 & 33 & 12 \\
\hline 20 & 123 & 52 & 8 & 330 & 120 & 0 & -34 & 33 & -33 & 33 & 12 \\
\hline 21 & 111 & 54 & 8 & 300 & 38 & 0 & -35 & 34 & -36 & 36 & 12 \\
\hline 22 & 118 & 54 & 8 & 300 & 53 & 0 & -35 & 34 & -36 & 36 & 12 \\
\hline 23 & 100 & 54 & 8 & 300 & 69 & 0 & -35 & 33 & -36 & 36 & 11 \\
\hline 24 & 94 & 54 & 9 & 300 & 87 & 0 & -34 & 33 & -36 & 36 & 12 \\
\hline 25 & 95 & 53 & 9 & 300 & 101 & 0 & -33 & 34 & -36 & 36 & 12 \\
\hline
\end{tabular}




\subsubsection{Função Gama do Plano 1}
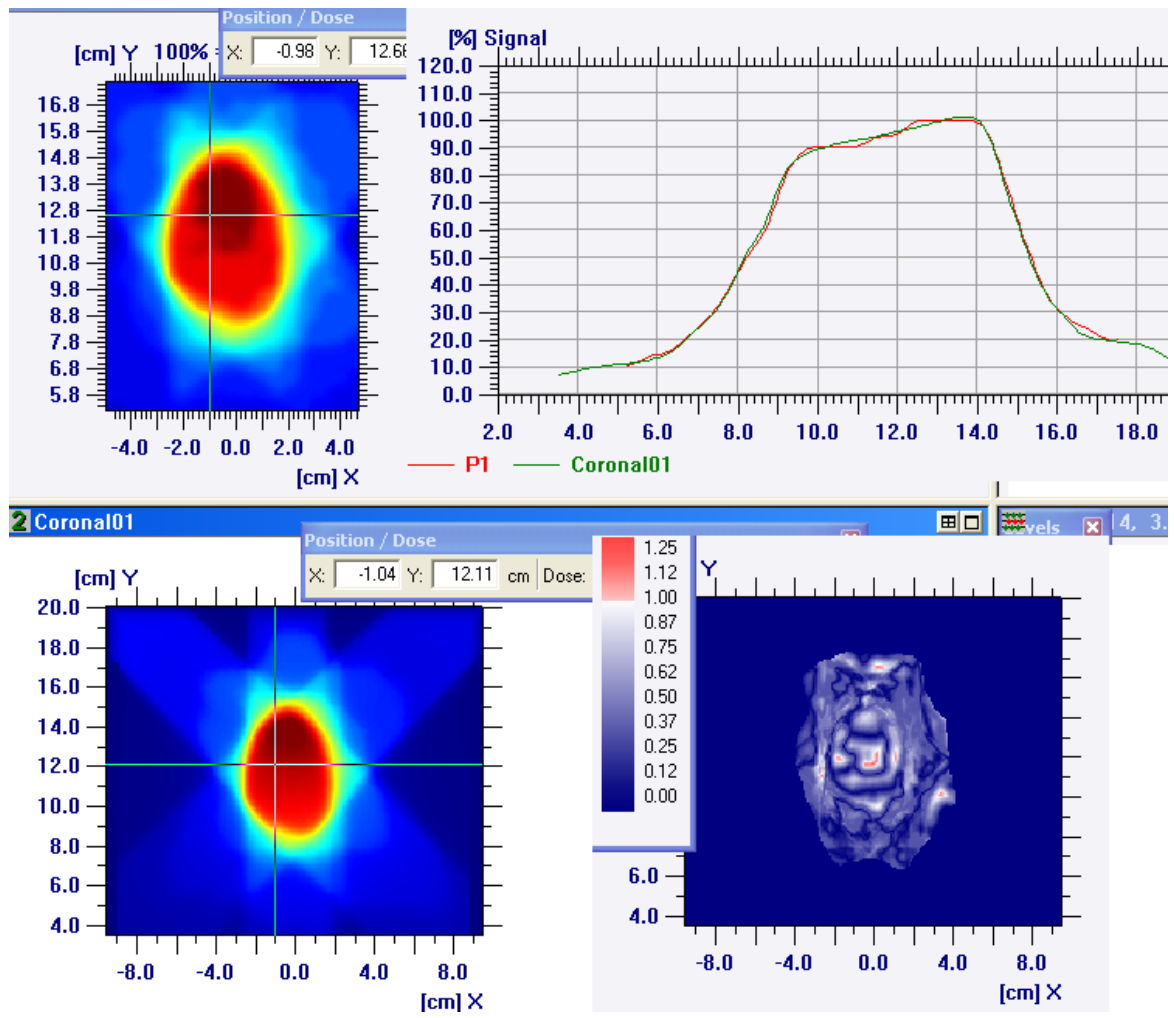

\subsubsection{Funcão Gama do Plano 2}

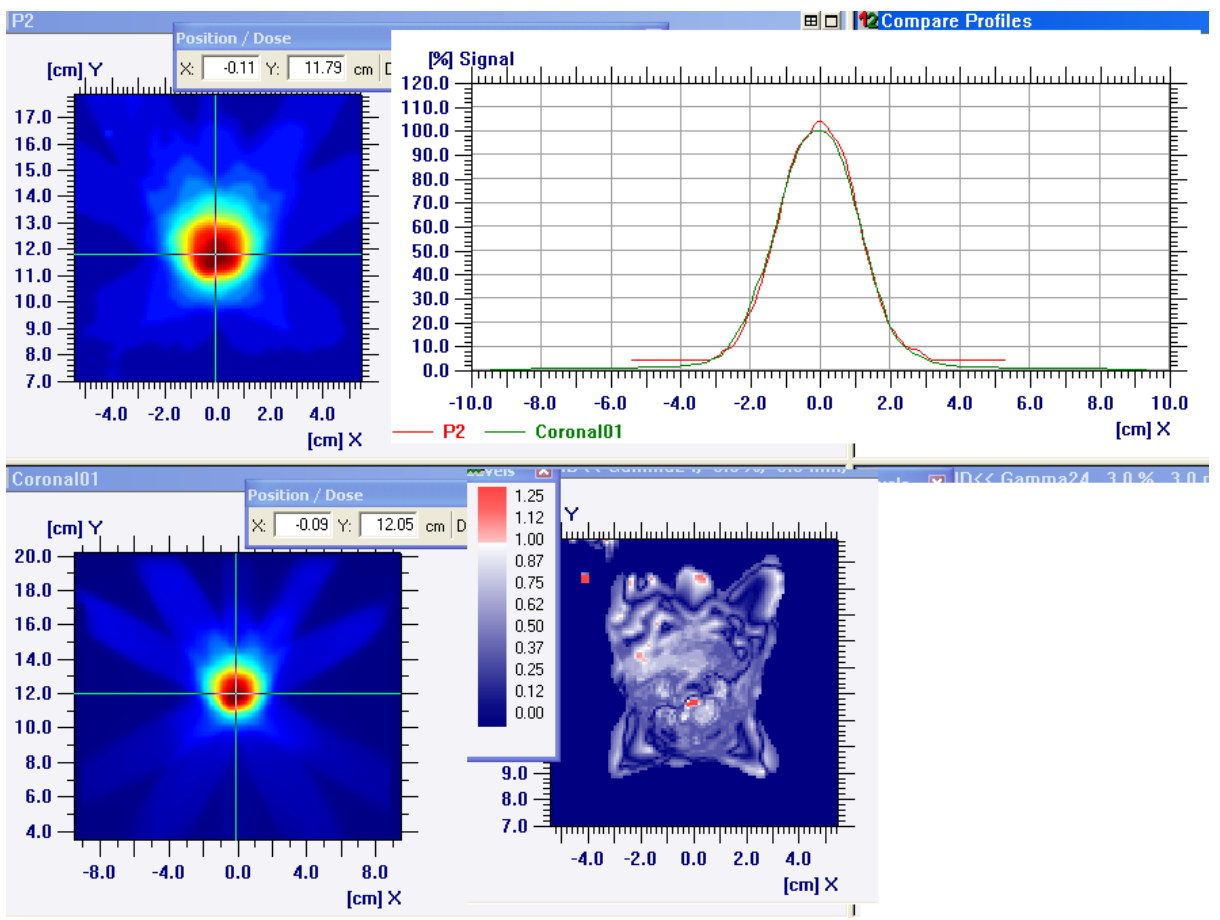




\subsubsection{Função Gama do Plano 3}

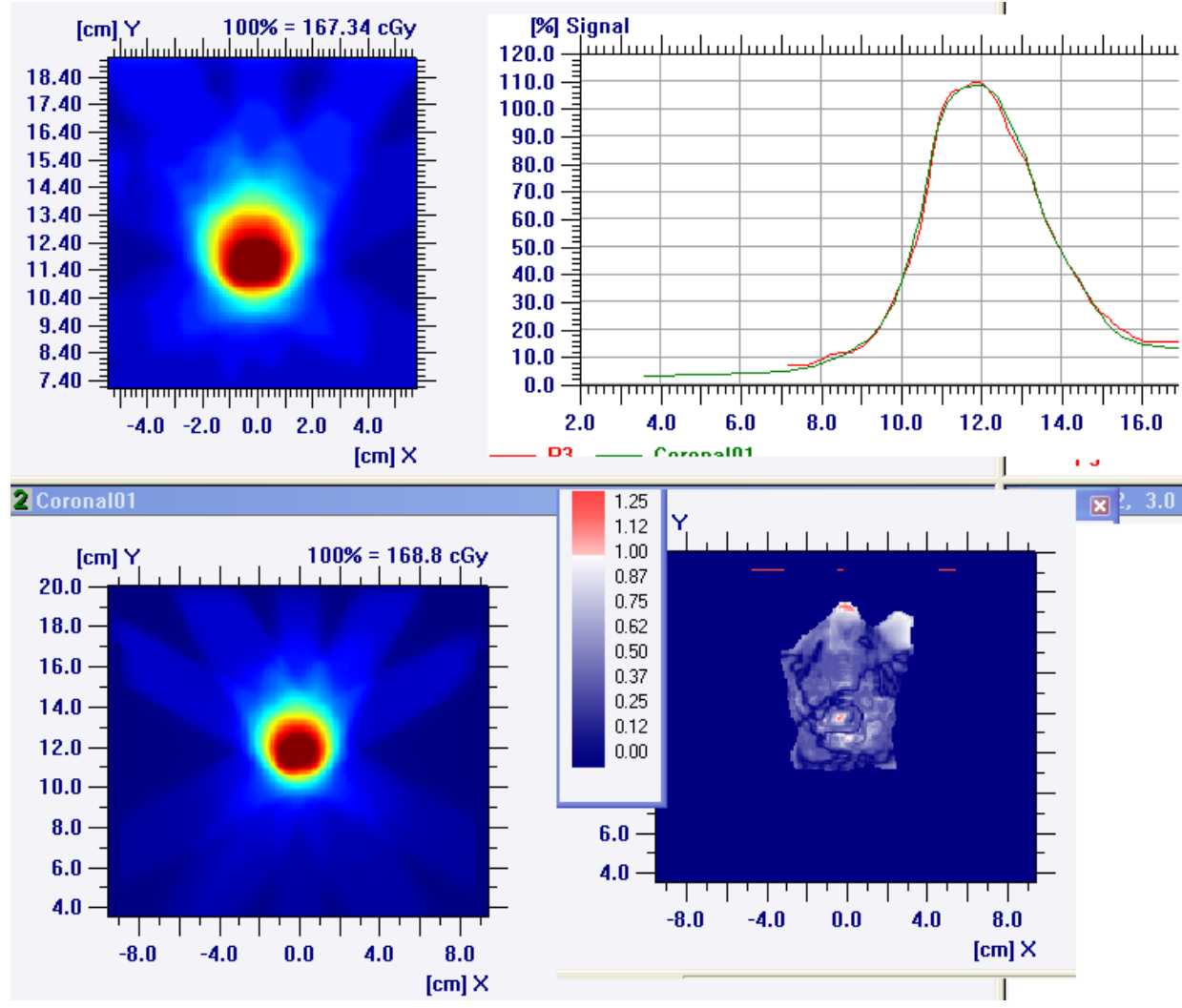

\subsubsection{Função Gama do Plano 4}



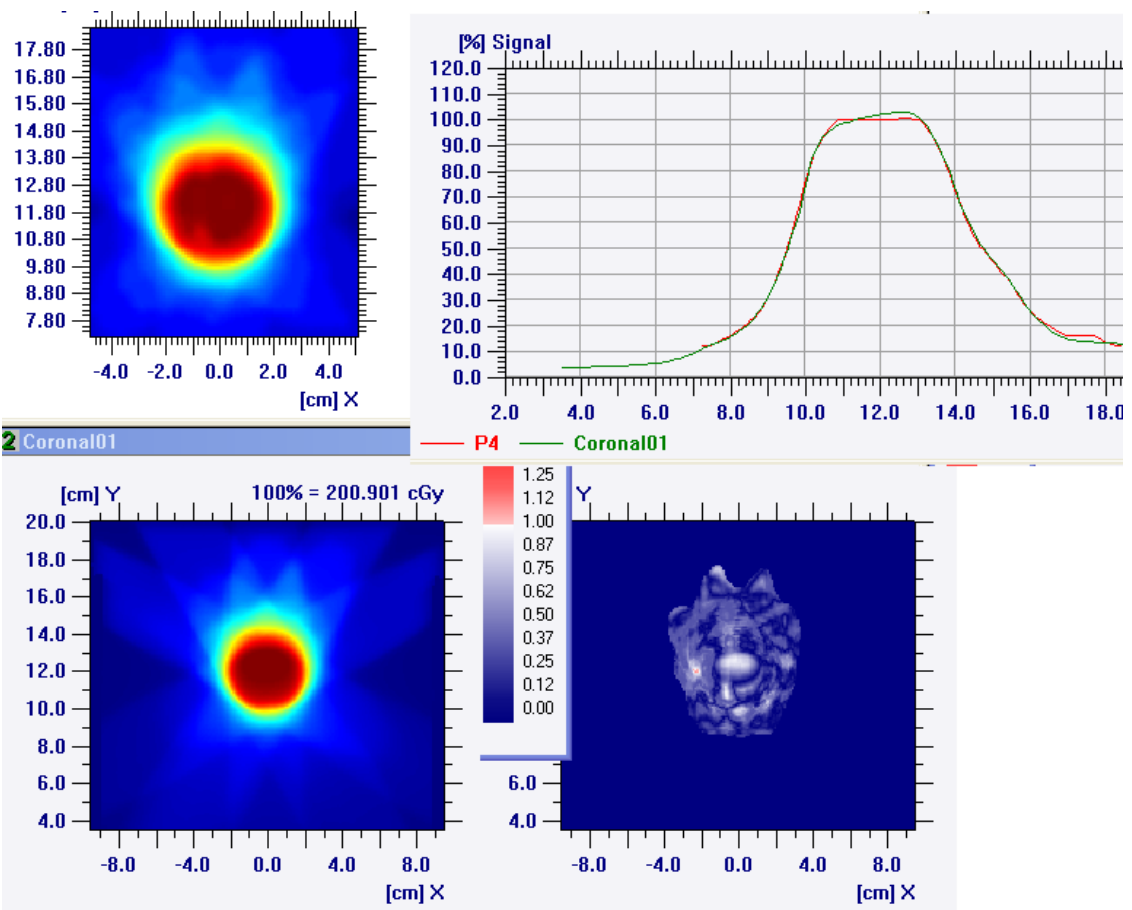

\subsubsection{Função Gama do Plano 5}

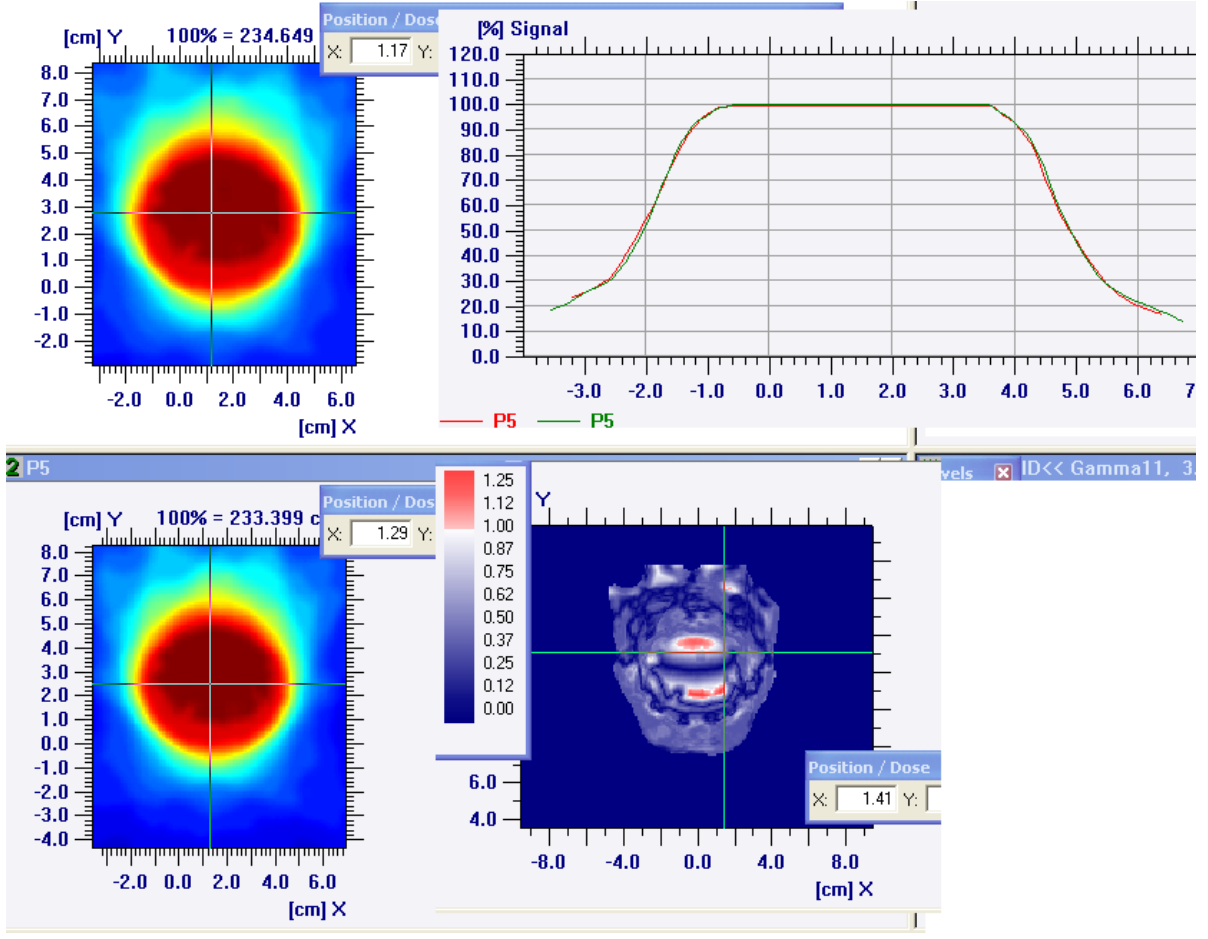

\subsubsection{Imagem da Planilha da dosimetria in vivo}



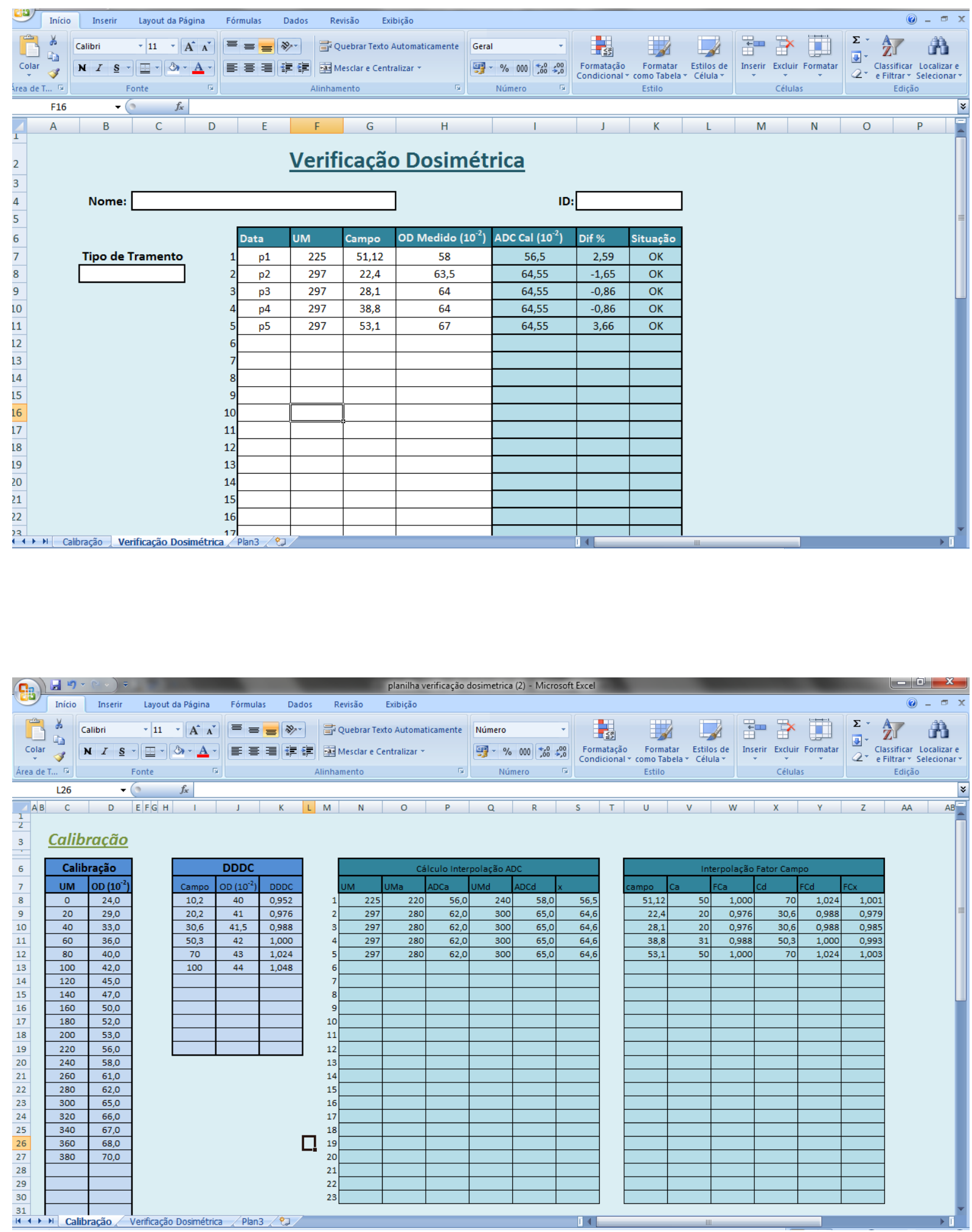